\title{
Satellite-derived parameters for biological modelling in coastal waters : Illustration over the eastern continental shelf of the Bay of Biscay
}

\author{
By Francis Gohin ${ }^{\mathrm{a},}$, Sophie Loyer ${ }^{\mathrm{b}}$, Michel Lunven ${ }^{\mathrm{a}}$, Claire Labry ${ }^{\mathrm{a}}$, Jean-Marie Froidefond ${ }^{\mathrm{c}}$, \\ Daniel Delmas ${ }^{\mathrm{d}}$, Martin Huret ${ }^{\mathrm{a}}$, and Alain Herbland ${ }^{\mathrm{d}}$ \\ ${ }^{\text {a }}$ Institut Français de Recherche pour l'Exploitation de la Mer, Departement d'Ecologie \\ Côtière, BP 70, 29280 Plouzane, Brittany, France \\ b Service Hydrographique et Océanographique de la Marine, CMO, BP 30316, 29603 Brest, \\ Cedex, Brittany, France \\ ${ }^{\mathrm{c}}$ Centre National de la Recherche Scientifique, UMR 5805, Université Bordeaux-1, Av. des \\ Facultés, 33405 Talence Cedex, France \\ d Institut Français de Recherche pour l'Exploitation de la Mer, Crema L'Houmeau, Case 5, \\ 17137 L'Houmeau, France \\ * corresponding author : Tel. : 33298224315 ; fax : 332984548 \\ E-mail address : Francis.Gohin@,ifremer.fr
}

\section{Keywords : Ocean color; Chlorophyll; Sediment; SeaWiFS; Bay of Biscay}

\begin{abstract}
In biological modelling of the coastal phytoplankton dynamics, the light attenuation coefficient is often expressed as a function of the concentrations of chlorophyll and mineral suspended particulate matter (SPM). In order to estimate the relationship between these parameters over the continental shelf of the northern Bay of Biscay, a set of in situ data has been gathered for the period 1998-2003 when SeaWiFS imagery is available. These data comprise surface measurements of the concentrations of total SPM, chlorophyll, and irradiance profiles from which is derived the attenuation coefficient of the photosynthetically available radiation, $K_{\text {PAR }}$. The performance of the IFREMER look-up table used to retrieve the chlorophyll concentration from the SeaWiFS radiance is evaluated on this new set of data. The quality of the estimated chlorophyll concentration is assessed from a comparison of the variograms of the in situ and satellite-derived chlorophyll concentrations. Once the chlorophyll concentration is determined, the non living SPM, which is defined as the SPM not related to the dead or alive endogenous phytoplankton, is estimated from the radiance at 555 $\mathrm{nm}$ by inverting a semi-analytic model. This method provides realistic estimations of concentrations of chlorophyll and SPM over the continental shelf all over the year. Finally, a relationship, based on non living SPM and chlorophyll, is proposed to estimate $\mathrm{K}_{\mathrm{PAR}}$ on the continental shelf of the Bay of Biscay. The same formula is applied to non living SPM and chlorophyll concentrations, observed in situ or derived from SeaWiFS radiance.
\end{abstract}




\section{Introduction}

Despite their well-known limitations in coastal waters, the ocean colour sensors provide a unique means for observing the phytoplankton distribution over the continental shelf. However, optical techniques from space platforms are hampered by clouds and can not be used alone for the monitoring of the phytoplankton all over the year. For that purpose, they need to be associated to biogeochemical models to be fully efficient. Satellite maps, calibrated on in situ measurements, can be used to validate and constrain the physical and biological parameters of the models or provide data for assimilation (Gregoire et al, 2003). In coastal waters, light is very often a key limiting factor for the phytoplankton growth and the light attenuation coefficient in the euphotic layer is a major parameter in ecological modelling. As we deal with biological simulations, the light is integrated over the PAR (Photosynthetically Available Radiation) domain [400, $700 \mathrm{~nm}$ ] and its attenuation coefficient is expressed as $\mathrm{K}_{\mathrm{PAR}}$. $\mathrm{K}_{\mathrm{PAR}}$ can be derived from the optically active components of water which are related to chlorophyll, SPM, and dissolved organic matter. The chlorophyll, as an indicator of the biological particles, and the inorganic SPM govern a large part of the absorption and scattering properties of the coastal waters. Both quantities are simulated in the coastal ecological models and can also be retrieved from ocean colour data.

The chlorophyll concentration in the Bay of Biscay has been routinely retrieved from SeaWiFS data for several years now by using a look-up table described in Gohin et al (2002). The SPM concentration can be derived from the reflectance at $555 \mathrm{~nm}, \mathrm{R}$ [555], as proposed for the Bay of Biscay by Froidefond et al. (2002). Considering that the phytoplankton, whose quantity is related to chlorophyll, is also a component of SPM, the relationship proposed by Froidefond et al. has to be modified to take into account the chl- $a$ concentration derived from the look-up table.

For modelling the availability of light with depth in the English Channel (Cugier, 1999; Cugier et al., 2004; Menesguen et al., 1995) and in the Bay of Biscay (Loyer, 2001), $\mathrm{K}_{\mathrm{PAR}}$ is calculated from the chlorophyll and the suspended matter concentrations (Prieur \& Sathyendranath, 1981; Nelson \& Smith, 1991). If we could express $K_{\mathrm{PAR}}$ by a combination of the chlorophyll, (Chl), and SPM concentrations, observed in situ or derived from satellite, we could also assimilate $K_{P A R}$ derived from both types of data. This paper presents some statistical properties of Chl, SPM, and $\mathrm{K}_{\mathrm{PAR}}$ over the continental shelf of the Bay of Biscay. The analysed properties will be the mean, the variance, and also the structure function, or variogram, which aims to expand the definition of the variance for space variables. These properties will be discussed from the observations and from the satellite derived quantities.

After having estimated the spatial distribution of the two optically active quantities that are Chl and SPM, we have tested the application of the Ocean Color 4 band algorithm (OC4) to the coastal waters of the Bay of Biscay. OC4 is an algorithm which has been defined to retrieve the chlorophyll concentration from the remote sensing reflectance in clear waters (O'Reilly et al., 1998). Clear waters, also called Case 1 waters, contain only pure water and phytoplankton particles (with their associated detrital material) which are well correlated with Chl. Although this algorithm has not been proposed for coastal waters, also called Case 2 waters, where the SPM and the yellow substances altered significantly the optical properties of the medium, it is largely applied without geographical restrictions. In many cases, the boundary between the water types is largely unknown and its seasonal evolution, from winter to summer, contributes to make the question still more complex. 


\section{The optical parameters derived from ocean colour}

In our coastal region, the optical properties of the water depend on three main constituents in addition to pure water itself: phytoplankton, inorganic suspended material, and yellow substances (dissolved organic matter). The contribution by phytoplankton to optical properties can also be divided into two components as coccoliths-bearing species have their own optical characteristics (Smyth et al., 2002). The ordinary phytoplankton component groups living cells and other microscopic organisms or particles whose concentration covaries with the chlorophyll-a pigment which is considered as representative of the whole component. Inorganic materials are transported from the land in the rivers plumes (mainly Loire, Gironde, and Adour) or resuspended from the bottom. Resuspension of SPM are observed in shallow waters subjected to strong tidal stirring or, more often in the Bay of Biscay, in mixed waters following frequent and energetic autumn and winter storms. Coccoliths are produced by a coccolithophore (Emiliana Huxleyi) abundant over the slope of the continental shelf. Their presence is regular in spring and summer over the Celtic Sea but they have also been observed closer to the coast in winter. The calcareous plates of the coccoliths are highly reflective at any wave length and are well discriminated from the satellite reflectance spectrum. The yellow substances are coloured dissolved organic matter. They may have a local origin, from degradation of plankton cells, or be advected in estuaries and river plumes.

The spectral diffuse attenuation coefficient of light $K(\lambda)$ depends on the concentration of the optically active constituents of water. It is defined as the rate at which the natural logarithm of the descending irradiance at wavelength $\lambda, \operatorname{Ed}(z, \lambda)$, is attenuated with depth following the Beer-Lambert law (Defant, 1961).

$$
\mathrm{K}(\mathrm{z}, \lambda)=-\frac{\mathrm{d}[\ln (\operatorname{Ed}(\mathrm{z}, \lambda))]}{\mathrm{dz}} \quad \text { where } \mathrm{z} \text { is depth (1) }
$$

$\mathrm{K}(\mathrm{z}, \lambda)$ is used to relate Ed (expressed in $\mathrm{W} \mathrm{m}^{-2}$ ) at depth $\mathrm{z}$ to the irradiance $\operatorname{Ed}(0, \lambda)$ just below the surface. By integrating (1) from the surface to a depth $z$, with $K(\lambda)$ constant with $\mathrm{z}$, one obtains :

$$
\mathrm{E}(\mathrm{z}, \lambda)=\mathrm{Ed}(0, \lambda) \exp [-\mathrm{K}(\lambda) \mathrm{z}]
$$

In biology, $\mathrm{K}_{\mathrm{PAR}}$ is defined as the rate at which the total quanta $\mathrm{Q}(\mathrm{z})$, integrated over the PAR domain, declines with depth.

$$
\mathrm{Q}(\mathrm{z})=\frac{1}{\mathrm{hc}} \int_{400}^{700} \operatorname{Ed}(\mathrm{z}, \lambda) \lambda \mathrm{d} \lambda
$$

where $\mathrm{h}$ is Planck's constant, $\mathrm{c}$ is the velocity of light. $\mathrm{Q}(\mathrm{z})$ is the flux of photons, expressed in $\mu$ Einstein, per square meter and per second.

The remote sensing reflectance, $\mathrm{R}_{\mathrm{RS}}(\lambda)$, is defined as the ratio of the upwelling radiance to the downwelling irradiance at the water surface. $\mathrm{R}_{\mathrm{RS}}(\lambda)$ depends on the back-scattering coefficient $b_{b}$ and the attenuation coefficient $a(\lambda)$ which are inherent optical properties, IOPs, of the medium. 


$$
\mathrm{R}_{\mathrm{RS}}(\lambda)=\mathrm{C} \frac{\mathrm{b}_{\mathrm{b}}(\lambda)}{\mathrm{a}(\lambda)+\mathrm{b}_{\mathrm{b}}(\lambda)}
$$

where $\mathrm{C}$ is a function of the zenith solar angle, the observation angle, and the surface roughness (Gordon et al., 1975, Morel et al., 1995). C is often, as in Sydor and Arnone (2002), considered as a constant for the sake of simplification.

$K(\lambda)$ can also be expressed as a function of the IOPs of the water

$K(\lambda)=\frac{a(\lambda)}{\mu_{0}}\left[1+\left(0.425 \mu_{o}-0.19\right) \frac{b(\lambda)}{a(\lambda)}\right]^{\frac{1}{2}}$ (5) from Kirk (1984), where $b(\lambda)$ is the scattering coefficient

As $b(\lambda)$ is generally much smaller than $a(\lambda), K(\lambda)$ is close to $\frac{a(\lambda)}{\mu_{0}}$.

In contrast to $\mathrm{a}, \mathrm{b}$, and $\mathrm{b}_{\mathrm{b}}, \mathrm{K}$ is an apparent optical property of the medium as it depends on the cosinus $\mu_{0}$ that the photons make with the vertical below the sea surface.

The contribution of the different materials to the total absorption and scattering coefficients is additive (Kirk, 1983). For example, in absence of coccoliths, the back-scattering coefficient $b_{b}(\lambda)$ can be partitioned into three components :

$$
b_{b}(\lambda)=b_{b w}(\lambda)+b_{b C h l}(\lambda)(C h l)+b_{b s} *(\lambda) n L v S P M(6)
$$

where $b_{b w}(\lambda)$ is the backscattering coefficient of pure water. $b_{b C h l}(\lambda)(C h l)$ is the backscattering coefficient of the phytoplankton cells related to their concentration in Chl, and $\mathrm{b}_{\mathrm{bS}}{ }^{*}$ is the mass-specific backscattering coefficient of nLvSPM (non Living Suspended Particulate Matter). nLvSPM is defined as the component of SPM which is not related to the dead or alive cells of phytoplankton. nLvSPM, is mainly mineral (inorganic SPM) but contains also exogenous organic matter in the rivers loads or in resuspended materials. nLvSPM will be derived from our in situ SPM measurements by subtracting a biogenic SPM expressed from observed Chl.

Similarly, the absorption coefficient is expanded as the sum of the coefficients of all the absorbing components of the medium which are water, Chl, nLvSPM, and yellow substances.

The absorption coefficient of yellow substances or CDOM (Colored Dissolved Organic Matter) decreases exponentially with the wavelength and the total absorption of the medium $\mathrm{a}(\lambda)$ can be expressed in the green channel $(555 \mathrm{~nm})$ as :

$\mathrm{a}=\mathrm{a}_{\mathrm{w}}+\mathrm{a}_{\mathrm{p}+\mathrm{y}}(\mathrm{Chl})+\mathrm{a}_{\mathrm{s}}{ }^{*} \mathrm{nLvSPM}+\mathrm{a}_{\mathrm{y}}\left(\lambda_{\mathrm{r}}\right) \exp \left(-\mathrm{S}\left[555-\lambda_{\mathrm{r}}\right]\right)$

where $a_{w}$ is the absorption coefficient of pure water, $a_{p+y}(\mathrm{Chl})$ the absorption coefficient of the phytoplankton (particles and endogenous yellow substances), $a_{\mathrm{s}}{ }^{*}$ the mass-specific absorption coefficient of $n L v S P M$, and $a_{Y}\left(\lambda_{r}\right)$ the absorption coefficient of the exogenous yellow substances at a reference wavelength $\lambda \mathrm{r}$ in the blue (often $443 \mathrm{~nm}$ ). Babin et al. (2003a) propose an exponential slope $\mathrm{S}$ of $0.0176 \mathrm{~nm}^{-1}$ for coastal waters around Europe. Despite their significant contribution to the total absorption in the river plumes, where 
nLvSPM concentration is also high, we will not consider the yellow substances separately from the chlorophyll and nLvSPM and will neglect the last term in Eq. (7).

\section{Criteria to assess the quality of the satellite derived estimations}

\subsection{Variance and Variogram}

To assess the quality of the estimation $Z^{*}(\mathrm{x})$ of the variable $\mathrm{Z}$ (Chl, SPM, or $\mathrm{K}_{\mathrm{PAR}}$ ) at location $\mathrm{x}$, we consider two criteria :

- the first criterion refers to the variance of the difference between $Z^{*}\left(x_{i}\right)$ and $Z_{\text {situ }}\left(x_{i}\right)$, where $\mathrm{x}_{\mathrm{i}}$ is a measurement location.

- the second criterion is based on the difference of the structure functions (semi-variograms) of $Z^{*}$ and $Z_{\text {situ. }}$.

The semi-variogram $\gamma(\mathrm{h})$ (hereafter the "variogram"), where $\mathrm{h}$ is a distance, is a representation of the spatial structure of $Z$ considered as a random variable subjected to measurement errors. The variogram describes how the autocorrelation of the variable $Z$ varies across space. Initially defined to characterise the spatial structure for resource assessment in the mining industry, the variogram is also widely used in remote sensing (Curran, 1988) for applications like optimal interpolation (Gohin \& Langlois, 1993), or sampling strategy (Hedger et al., 2001).

The experimental variogram is obtained by calculating the variance of the increments $[\mathrm{Z}(\mathrm{x}+\mathrm{h})-\mathrm{Z}(\mathrm{x})]$ as a function of the distance $\mathrm{h}$ :

$\gamma(h)=\sum_{i=1}^{i=n} \frac{\left[Z\left(x_{i}+h\right)-Z\left(x_{i}\right)\right]^{2}}{2 n}$

where $\mathrm{n}$ is the number of couples of points separated by the distance $\mathrm{h}$; e.g. if $\mathrm{h}=10$ all points that are $10 \pm 0.5$ units apart are used to estimate $\gamma(\mathrm{h})$

As distance increases, the variance between pixels pairs increases (Fig. 1). The variance of the measurement $Z_{\text {situ }}(x)$ around the true unknown value $Z(x), \sigma_{\text {situ }}{ }^{2}$, can be approximated from the apparent jump of the variogram at the origin $\gamma_{\text {situ }}(0)$. This jump is known in geostatistics as the nugget effect. It can be related to the variance of the noise including the effects of microstructures (phenomenon similar to nuggets and not visible at the scale of our sampling) and measurement errors.

The nugget effect could be a good estimation of $\sigma_{\text {situ }}{ }^{2}$ if the in situ data were not acquired locally by the same ship. From (8) we can write, after adding and subtracting the unknown $\mathrm{Z}(\mathrm{x})$,

$$
\gamma_{\text {situ }}(0)=\lim \left(\sum_{\mathrm{i}=1}^{\mathrm{i}=\mathrm{n}} \frac{\left[\mathrm{Z}_{\text {situ }}\left(\mathrm{x}_{\mathrm{i}}+\mathrm{h}\right)-\mathrm{Z}(\mathrm{x})-\left(\mathrm{Z}_{\text {situ }}\left(\mathrm{x}_{\mathrm{i}}\right)-\mathrm{Z}(\mathrm{x})\right)\right]^{2}}{2 \mathrm{n}}\right) \text { for } \mathrm{h} \text { tending to } 0 \text { and } \mathrm{n} \text { to }
$$
infinity (9)

Which gives $\gamma_{\text {situ }}(0)=\sigma_{\text {situ }}{ }^{2}-\operatorname{cov}\left[Z_{\text {situ }}(x+h)-Z(x), Z_{\text {situ }}(x)-Z(x)\right]$ for h small (10)

The last term in the equation is related to the covariance of the measurement errors of a same ship. Therefore, the nugget effect is a minorant of $\sigma_{\text {situ }}^{2}$.

As the local errors of our variables are roughly proportional to the local average and the distributions highly asymmetric and ranging over several orders of magnitude, the 
comparisons of structures will be based on log-transformed data. The unit of the distance is the size of the SeaWiFS pixel $(1.1 \mathrm{~km})$ which is also the size of the mesh of the grid over which the images are projected.

Fig.1. Schematic of the variogram

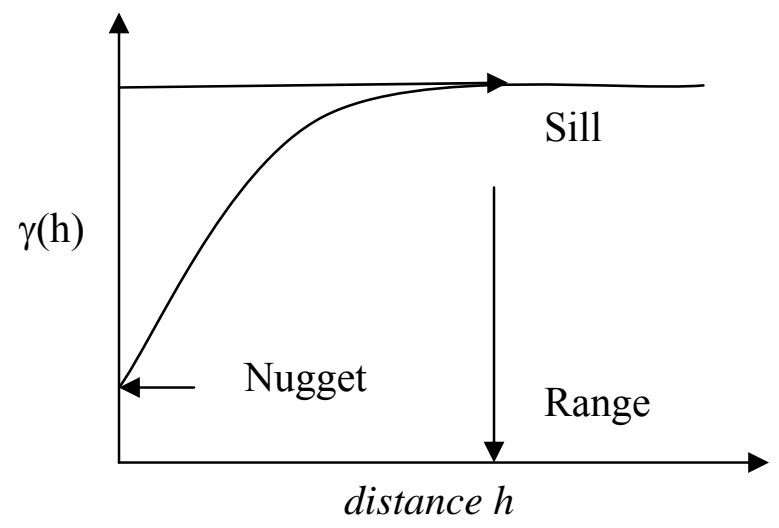

The variogram is used in geostatistics to derive optimal estimators of geophysical variables. For such applications, the stationarity of the increments and the "intrinsic hypotheses", set up in (8), are particularly required. That implies that the increments $[\mathrm{Z}(\mathrm{x}+\mathrm{h})-\mathrm{Z}(\mathrm{x})]$ have a zero mean, at any $\mathrm{x}$ and $\mathrm{h}$, and for any realisation of the variable $\mathrm{Z}$. This is particularly true for the chlorophyll which shows a regular variation in space and time (except in the less productive months of December and January where the chlorophyll patterns depart significantly from the mean situation) but poorly verified for the inorganic SPM which is concentrated in the river plumes and near the coast. For the sake of comparing observed and estimated variables, we will focus on the behaviours of the variograms at the origin, for small $h$, and mentioned them only for assessing their structures and providing confidence intervals.

\subsection{Estimating a 90\% confidence interval for Z $(x)$ from the satellite-derived estimation}

To calculate the variance of the error occurring from estimating $\mathrm{Z}(\mathrm{x})$ by $\mathrm{Z}_{\mathrm{sat}}(\mathrm{x})$, we begin by expanding the deviation $\left[\mathrm{Z}_{\mathrm{sat}}(\mathrm{x})-\mathrm{Z}_{\text {situ }}(\mathrm{x})\right], \Delta$, into two independent terms :

From $\Delta=\left[\mathrm{Z}_{\mathrm{sat}}(\mathrm{x})-\mathrm{Z}(\mathrm{x})\right]-\left[\mathrm{Z}_{\mathrm{situ}}(\mathrm{x})-\mathrm{Z}(\mathrm{x})\right]$, it follows that $\operatorname{Var}(\Delta)=\operatorname{Var}\left[\mathrm{Z}_{\mathrm{sat}}(\mathrm{x})-\mathrm{Z}(\mathrm{x})\right]+\sigma_{\text {situ }}{ }^{2}$ (11)

As $\sigma_{\text {situ }}^{2}$ is minored by $\gamma_{\text {situ }}(0)$, we obtain from (11) :

$\operatorname{Var}\left[Z_{\text {sat }}(\mathrm{x})-\mathrm{Z}(\mathrm{x})\right]=\operatorname{Var}(\Delta)-\sigma_{\text {situ }}^{2} \leq \operatorname{Var}(\Delta)-\gamma_{\text {situ }}(0)$

Considering that the errors are gaussian, we can derive a $90 \%$ (more in fact) confidence interval for $\mathrm{Z}(\mathrm{x})$ (for instance, the log-transformed chlorophyll concentration),

$$
90 \% \text { Confidence Interval }=\left[Z_{\text {sat }}(\mathrm{x}) \pm 1.64 \sqrt{\operatorname{Var}(\Delta)-\gamma_{\text {situ }}(0)}\right]
$$




\section{The data sets}

\subsection{The in situ data set}

Most of the surface data acquired during the oceanic cruises carried out in the eastern Bay of Biscay since the launch of SeaWiFS, at the end of 1997, have been gathered in a file grouping the concentrations of chlorophyll, phaeopigments, SPM, and $\mathrm{K}_{\mathrm{PAR}}$. Dates of each cruise are given in Table 1 and locations of the points are shown on Fig. 2. The number of data is 1017, 854, 430 for chlorophyll, SPM, and $\mathrm{K}_{\mathrm{PAR}}$ respectively. These cruises have mainly sampled the late winter and spring situations. The MODYCOT cruises have been carried out by the Hydrographic and Oceanographic Centre of the French Navy (EPSHOM). Most of the IFREMER cruises (GASPROD, NUTRIGAS, PEL) are linked to the Bay of Biscay IFREMER or PNEC (Programme National d'Environnement Côtier) projects.

Hydrology measurements are carried out with a Seabird CTD to which are connected a fluorimeter (Chelsea Instrument) and a quantameter immersed on the bathysonde. The quantameters used to measure the downwelling irradiance is an underwater quantum sensor LICOR (LI-192 SA) or a light sensor Biospherical QSP-200. Additional chemical samplings have been taken with Niskin bottles.

Table 1: The periods sampled by the 20 cruises

\begin{tabular}{|c|c|c|c|c|c|c|c|c|c|c|c|c|}
\hline & & 1 & 2 & 3 & 4 & 5 & 6 & 7 & 8 & 9 & 10 & 11 \\
\hline 1998 & $\begin{array}{l}\text { BIOMET } 2 \\
\text { BIOMET } 3 \\
\text { PEGASE }\end{array}$ & & & & & & & & & & & \\
\hline 1999 & $\begin{array}{c}\text { PLAGIA 1 } \\
\text { MODYCOT 99-1 } \\
\text { PLAGIA 2 } \\
\text { MODYCOT 99-2 } \\
\text { PLAGIA 4 } \\
\text { PLAGIA 5 }\end{array}$ & & & & & & & & & & & \\
\hline 2000 & $\begin{array}{l}\text { MODYCOT } 00 \\
\text { PEL T0 }\end{array}$ & & & & & & & & & & & \\
\hline 2001 & $\begin{array}{c}\text { NUTRIGAS } \\
\text { MODYCOT 01-1 } \\
\text { PEL 01 } \\
\text { MORBRAS } \\
\text { MODYCOT 01-2 }\end{array}$ & & & & & & & & & & & \\
\hline 2002 & $\begin{array}{c}\text { GASPROD } \\
\text { MODYCOT } 02\end{array}$ & & & & & & & & & & & \\
\hline $290 \%$ & $\begin{array}{l}\text { MODYCOT 03 } \\
\text { Ophylleor an }\end{array}$ & M & & & & & & & & & & \\
\hline
\end{tabular}

During the MODYCOT cruises, seawater samples for pigments analysis are filtered onto 25 $\mathrm{mm} \mathrm{GF} / \mathrm{F}$ glass fibre filters (Wathman) using a vacuum filtration system. During filtration, vacuum does not exceed $200 \mathrm{mbar}$ to prevent the destruction of phytoplankton cells. Filters are stored immediately at $-20{ }^{\circ} \mathrm{C}$ on board for the duration of the cruise. Chlorophyll $a$ is extracted and analysed by the reverse-phase HPLC method slightly modified from Wright et al. (1991). This procedure has also been applied to the samples of most of the other cruises.

For some cruises, samples are collected with $47 \mathrm{~mm} \mathrm{GF} / \mathrm{F}$ glass fibre filters (Wathman) and analysed later by the fluorimetric acidification procedure in $90 \%$ acetone extract. Suspended particulate matter are estimated as dry weight $\left(60^{\circ} \mathrm{C}, 24 \mathrm{H}\right)$ after a filtration on a preweighted $47 \mathrm{~mm}$ Whatman GF/F. Filters are rinsed rapidly after filtration with a solution of ammonium formiate before being frozen. If filters are not sufficient rinsed, the weight could be 
overestimated due to the remaining salts. Therefore, the ammonium formiate solution is optimal to eliminate salts, as much as possible, while preventing cell lysis (Etcheber, 1981). Nevertheless, 3 cruises (PEGASE, PLAGIA4 and PEL01) have shown excessive SPM concentrations in the oceanic area of the Bay of Biscay and have been entirely removed from our data set.

\section{The irradiance profile and the estimation of $K_{P A R}$}

$\mathrm{K}_{\mathrm{PAR}}$ is not constant with depth and its variation can be related to :

- change in the spectral distribution of photons with depth.

- modifications of optical properties which depend on the type and the water components, primarily of phytoplankton, suspended sediment and dissolved and particulate organic material.

- change in the geometric structure of the light field as the proportion of the direct sunlight diminishes with depth.

Fig. 3 shows three irradiance profiles collected during the cruise MODYCOT03 in March, 2003. Fig. 3a shows two typical profiles made in homogeneous waters (located on Fig. 2). The profile on the right (case a) corresponds to relatively clear water, with concentration of $0.77 \mathrm{~g}$ $\mathrm{m}^{-3}$ and $0.45 \mathrm{mg} \mathrm{m}^{-3}$ for suspended matter and chlorophyll $a$ respectively. The profile on the left is representative of a water highly loaded in sediment, with concentration of $8.6 \mathrm{~g} . \mathrm{m}^{-3}$ and $0.7 \mathrm{mg} \mathrm{m}^{-3}$ for suspended matter and chlorophyll $a$ respectively. The profile shown on Fig. $3 \mathrm{~b}$ is less typical. The suspended matter and chlorophyll concentrations are respectively $2.7 \mathrm{~g} \mathrm{~m}^{-3}$ and $0.4 \mathrm{mg} \mathrm{m}^{-3}$ at the surface.

Fig. 2. Spatial distribution of the in situ data with the 200 -meter isobath and the most significant rivers indicated

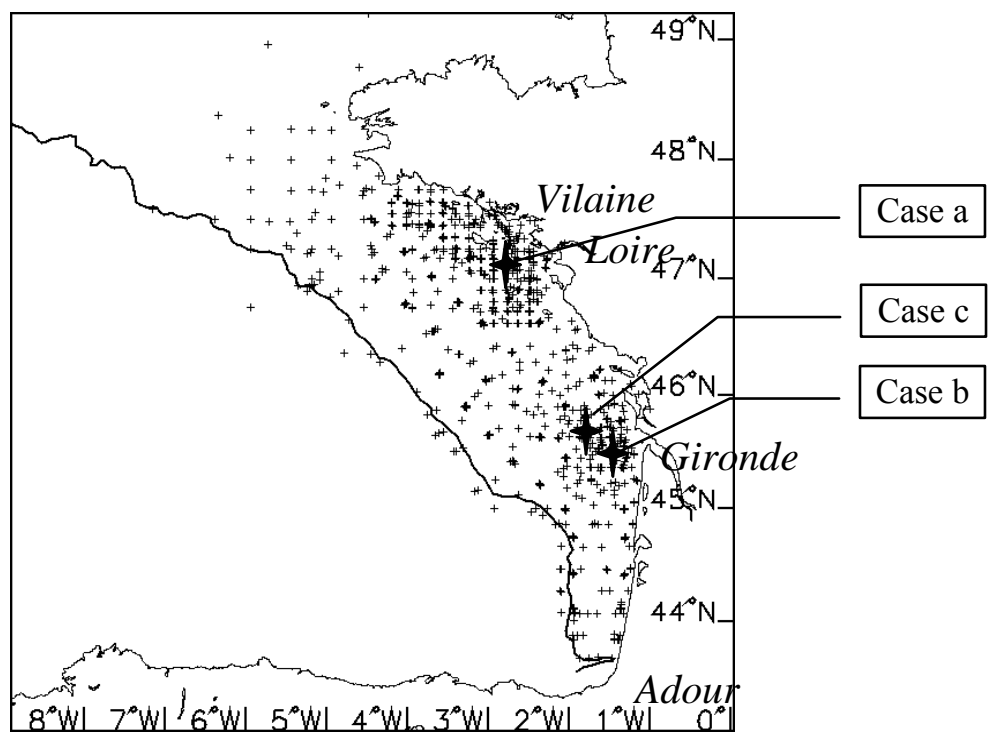

The lack of irradiance measurement in the first 3 meters does not enable us to observe the strong attenuation of the longer visible wavelengths in the sub surface. In the first case of Fig. 
3 (Fig. 3a right) sunlight is present down to 35 meters (about $1 \%$ of the subsurface light), while in the second case (Fig. 3a left) it is lower than $1 \%$ at about 10 meters. We can distinguish five layers with different slopes on Fig. $3 b$. Higher $K_{P A R}$ are found in the first and last layers. The less saline surface layer is more turbid, being loaded by sediments advected by the river plume. Near the bottom, the light intensity is highly absorbed by flocculent sediments that are resuspended by tide and the action of waves.

To calculate $K_{\text {PAR }}$ on those different profiles, we have considered the profile of the logtransformed irradiance over a representative depth $\mathrm{D}$. This length $\mathrm{D}$ has been defined as the depth where the remaining light is equal to about $10 \%$ of the light under the surface. For estimating D, a first attenuation coefficient $\mathrm{K}_{\mathrm{PAR} 1}$ is obtained from the regression of the logtransformed irradiance observed over the upper 20 meters. Then, D is defined as $\log _{N}(10) / K_{\text {PAR1 }}$, following Eq. (2). The final $K_{\text {PAR }}$ is calculated as the slope of the regression of the log-transformed irradiance over the depth D. Fig. 3 shows different irradiance profiles and their associated D. Different representative depths D could have been proposed but, by choosing the depth corresponding to the $10 \%$ threshold, we calculate a $\mathrm{K}_{\mathrm{PAR}}$ over a depth range which can be related to the depth really observed by the satellite sensor. Given our mean $\mathrm{K}_{\mathrm{PAR}}$ of $0.25 \mathrm{~m}^{-1}$, and considering that about $90 \%$ of the water leaving radiance at wavelength $\lambda$ originates from the water layer comprised between the surface and the depth $1 / \mathrm{K}(\lambda)$ (Gordon \& Mc Cluney, 1975), the optical depth remotely sensed is about $4 \mathrm{~m}$ in our sample. The $10 \%$ isolume is at $9.2 \mathrm{~m}$ and the euphotic layer ( $1 \%$ isolume) is $18.4 \mathrm{~m}$ deep.

Fig. 3. Typical irradiance profiles in logarithm. Irradiance is in $\mu$ Einstein $\mathrm{s}^{-1} \mathrm{~m}^{-2}$. (a) correspond to clear (right) and particle loaded (left) waters. (b) corresponds to a more complex case with a distinct surface layer. The horizontal bar indicates the maximum depth $\mathrm{D}$ over which $\mathrm{K}_{\mathrm{PAR}}$ is calculated.
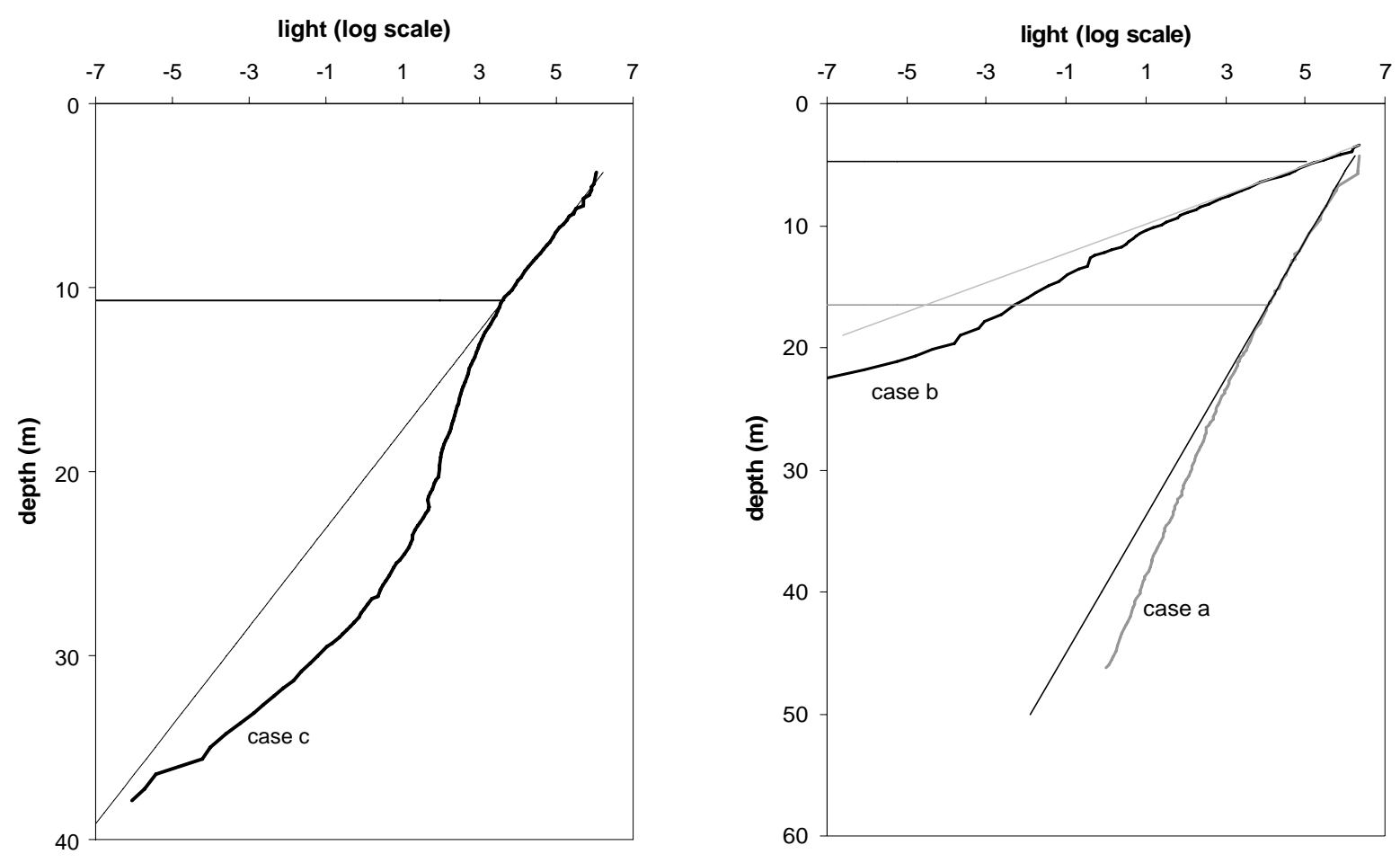


\section{Chlorophyll-a}

The SeaWiFS reflectance, or the normalised water leaving radiance from which it is derived, will be used to retrieve Chl and SPM. The reflectance at 412, 443, 490, 510 and 555 $\mathrm{nm}$ is obtained by applying SeaDAS 4.0 to the SeaWiFS Level 1A images (Top of atmosphere radiance) corresponding to each day of the cruises. The standard SeaDAS cloud flag is applied without any specific selection of the images that could have taken into account their atmospheric "quality". Although new versions of SeaDAS have been made available since version 4.0, this version will be applied here since we have observed that the gain in accuracy obtained in the reflectance after applying SeaDAS 4.3 was accompanied by an increased noise at $412 \mathrm{~nm}$. Our empirical approach to retrieve the chlorophyll concentration is based on a look-up table which accepts negative values, at $412 \mathrm{~nm}$ or at longer wavelength. The method is derived from OC4 after including the channels at 412 and $555 \mathrm{~nm}$. The 412 band provides an indicator of the atmospheric over-correction, which, added to the absorption by the yellow substances, alters the reflectance ratios used as inputs in OC4. Both errors covary more or less and, combined with the effect of the suspended matter, lead to a diminution of the reflectance ratios, erroneously related to chlorophyll pigments, providing an overestimation of the chlorophyll concentration by OC4. In the look-up table, triplets defined by (OC4 maximum band ratio, 412 and 555 reflectance) are related to chlorophyll concentrations. The look-up table has been calculated by interpolation between surfaces fitted from observations for chlorophyll iso-concentration classes $(0.1,0.2,0.4,0.6,1,2.5,5,10$, $\left.15,25 \mathrm{mg} / \mathrm{m}^{3}\right)$.

\section{The non living SPM}

SPM is divided into two compartments comprising chlorophyll and derivative particles for one, and exogenous (organic and mineral) particles for the other. From the chlorophyll concentration, we can calculate a minimum value for SPM corresponding to the phytoplankton biomass, LvSPM, grouping living cells and associated detrital particles.

To calculate LvSPM we relate Chl to the living and associated Particulate Organic Carbon, POC, and then convert the POC, expressed in $\mathrm{mg} \mathrm{C} \mathrm{m}^{-3}$, to biomass.

$$
\operatorname{LvSPM}=[\operatorname{LvSPM}: \mathrm{POC}] * \mathrm{POC}(\mathrm{Chl})
$$

where [LvSPM : POC] is the average ratio of the dry weight of phytoplankton to carbon. A contribution of $\mathrm{C}$ to the biomass of the phytoplancton equal to $36 \%$ can be deduced from the average composition of phytoplankton $\left(\mathrm{CH}_{2} 0\right)_{106}\left(\mathrm{NH}_{3}\right)_{16} \mathrm{H}_{3} \mathrm{PO}_{4}$ proposed by Redfield et al. (1963). However, this percentage is species-dependent; for instance it is lower in diatoms where silicium contributes significantly to the biomass. It depends also on the state of LvSPM at the time of measurement as $\mathrm{N}$ and P-compounds of the organic matter are rapidly degraded relatively to $\mathrm{C}$. Babin et al. (2003b) use a constant of 2.6 to convert POC into organic SPM and this value will be also our mean [LvSPM : POC] ratio.

Using a formula established in case 1 water (Morel, 1988), we consider :

$$
\operatorname{POC}(\mathrm{Chl})=90 \mathrm{Chl}^{0.57} \quad\left(\text { for } \mathrm{Chl} \text { in } \mathrm{mg} \mathrm{m}^{-3}\right. \text { ) }
$$


From (14) and (15), it follows : $\mathrm{nLvSPM}=\mathrm{SPM}-234 \mathrm{Chl}^{0.57}$

Once the chlorophyll concentration is determined, the reflectance at $555 \mathrm{~nm}$, also linearly related to the SeaWiFS water leaving radiance $\mathrm{nLw}$ [555], can be calculated from the concentration of nLvSPM, after adjustment of the parameters in relations (4), (6), and (7). Therefore we obtain a direct relationship between the water leaving radiance and nLvSPM.

Therefore, we proceed in two steps for estimating nLvSPM.

First step, we estimate the parameters of the regression of $\frac{b_{b}[555]}{a[555]+b_{b}[555]}$, a reflectance term noted $\mathrm{R}^{*}(555)$ later in the text, onto the water leaving radiance at $555 \mathrm{~nm} \mathrm{nLw}[555]$. For that purpose, we calculate pairs of data (Chl, nLvSPM) from the in situ measurements of chlorophyll-a and SPM. Using a first set of absorption and back-scattering coefficients from the literature, we calculate the theoretical $\mathrm{R}^{*}(555)$ for each pair (Chl, nLvSPM). Then, we estimate the parameters $\alpha_{0}$ and $\alpha_{1}$ of the linear regression between $R^{*}(555)$ and the satellite $\mathrm{nLw}[555]$ :

$\mathrm{R} *(555)=\alpha_{0}+\alpha_{1} \mathrm{nLw}[555]$ (17)

In the second step, we estimate $\mathrm{nLvSPM}$ by inverting $\mathrm{R}^{*}(555)$ derived from the regression on $\mathrm{nLw}[555]$ and using (6) and (7)

$$
\mathrm{nLvSPM}=\frac{\left(\alpha_{0}+\alpha_{1} \mathrm{nLw}[555]\right)\left[\mathrm{a}_{\mathrm{w}}+\mathrm{a}_{\mathrm{P}+\mathrm{Y}}(\mathrm{Chl})\right]-\left[\mathrm{b}_{\mathrm{bw}}+\mathrm{b}_{\mathrm{bChl}}(\mathrm{Chl})\right]}{\mathrm{b}_{\mathrm{bS}}{ }^{*}-\mathrm{a}_{\mathrm{S}}{ }^{*}\left(\alpha_{0}+\alpha_{1} \mathrm{nLw}[555]\right)}
$$

The light attenuation coefficient $K_{P A R}$

Following Bowers and Mitchelson-Jacob (1996), who derive $\mathrm{K}_{\mathrm{PAR}}$ from $\mathrm{K}(550)$, and $\mathrm{K}(550)$ from the absorption a(555), we write :

$$
\mathrm{K}_{\mathrm{PAR}}=\mathrm{k}_{1}+\mathrm{k}_{2} \mathrm{a}(555)
$$

Another common way for estimating $\mathrm{K}_{\mathrm{PAR}}$ is based on a direct expression of radiance ratios. $\mathrm{K}[490]$ can be derived from the ratio of the SeaWiFS reflectance R[490]/R[555] (Mueller 2000). However, this approach is limited to clear oceanic water where phytoplankton and associated products dominate optical properties of the water. 


\section{Results}

\subsection{Observed relationship between in situ chlorophyll and SPM}

The line $\mathrm{Y}=234 \mathrm{X}^{0.57}$ is superposed, on Fig. 4, on the scatterplots of SPM versus Chl (225 pairs of data). This line seems to constitute a reasonable approximation of the LvSPM. We see on Fig. 4 that the phytoplankton is often less important in mass than the other components that are mineral particles or exogenous organic matter.

Fig. 4. SPM versus Chl. The line $\mathrm{Y}=234 \mathrm{X}^{0.57}$ provides an approximation of the organic SPM related to phytoplankton. High chlorophyll concentrations correspond to rivers plumes in spring where the inorganic suspended sediment is neither low nor high.

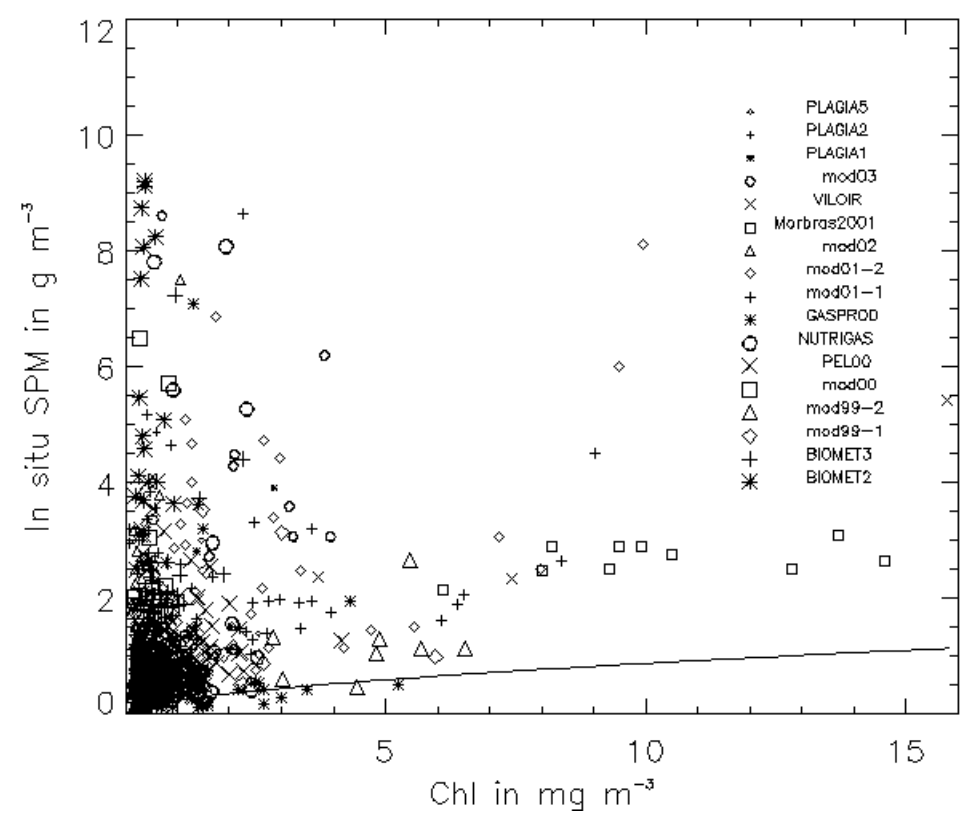

\subsection{The spatial structure of the chlorophyll concentration observed in situ}

As $\mathrm{Chl}$ at the surface is a 3-D variable, we have calculated several variograms corresponding to pairs of in situ data separated by different time lags.

Fig.5 shows the variogram of $\mathrm{Chl}$ for pairs of data separated by less than 12 hours (Fig. 5a), between 12 and 24 hours (see Fig. 5b), and between 24 and 36 hours (Fig. 5c).

We observe that the larger the lag time, the more numerous the pairs of data at long distance. This is due to the different numbers of couples available along the ships routes with time. As the lag time increases, from less to more than 12 hours, the loss in structure is significant for short distance. A linear trend, with a slope of 0.006 and an intersect at the origin (nugget) of 0.1 , fits well the best experimental variogram (see Fig. 5a) observed, as expected, for the smallest time lag. 
Fig. 5. Variograms of surface Chl- $a$, expressed in logarithm, for different time lags. (a) for pairs of data separated from 0 to 12 hours; (b) 12 to 24 hours ; (c) 24 to 36 hours The estimated value of $\gamma($ h) is shown by a cross if 50 pairs of data are present in the distance interval $[\mathrm{h} \pm 2$ pixels]
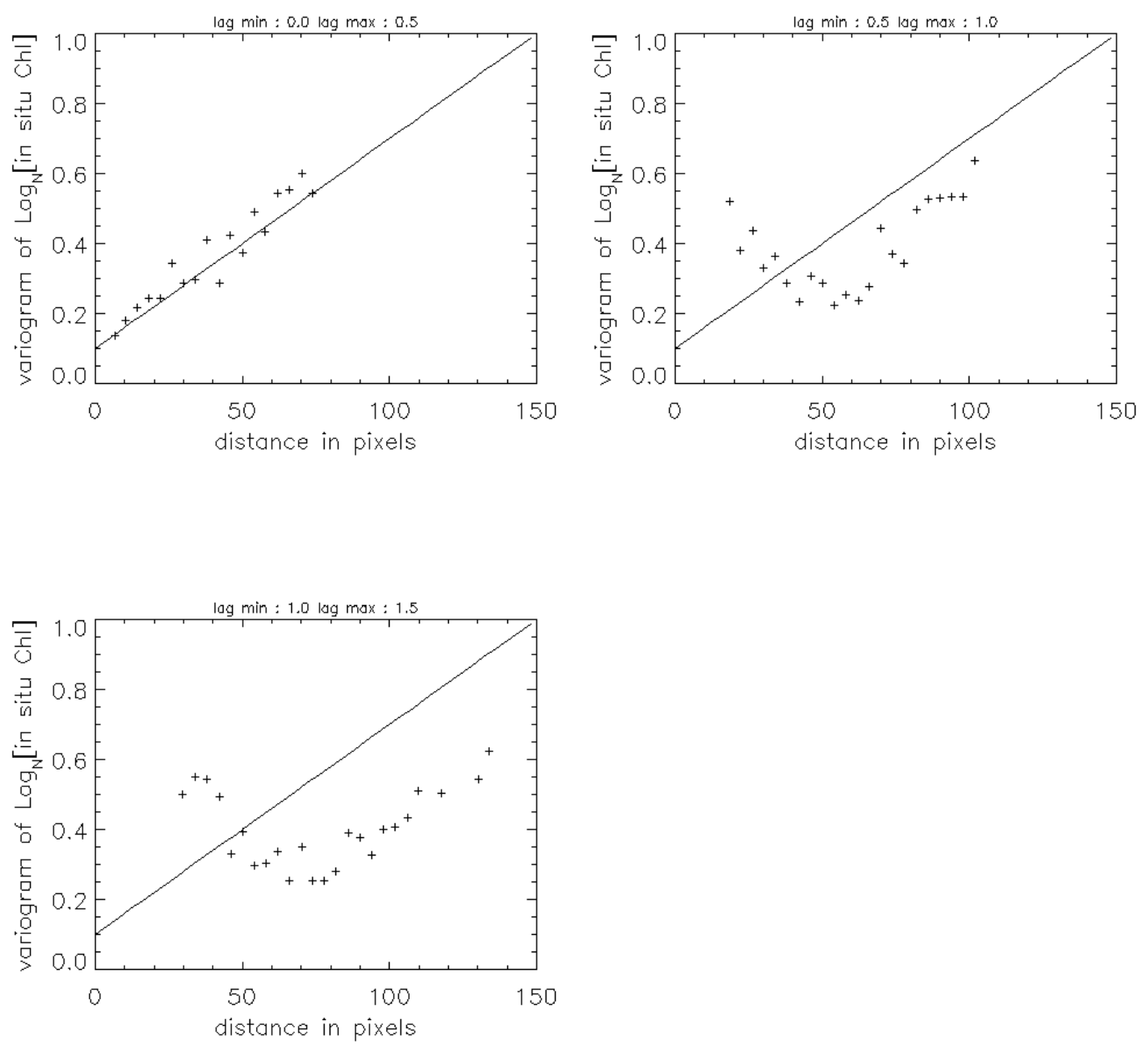

\subsection{The chlorophyll concentration derived from the look-up table}

Fig. 6 shows the scatterplots of the satellite-derived Chl versus in situ measurements using the empirical look-up table. The couples of in situ and satellite-derived data are obtained from measurements made the same day. As the polar-orbiting satellite covers the area in the middle of the day, the difference in the observation times is mostly less than 12 hours.

The means of the pairs of in situ and satellite data are shown in Table 2. Fig. 7 shows the variogram of the chlorophyll concentration derived from SeaWiFS. To estimate the experimental variogram of the satellite-derived chlorophyll concentration, we have built a new set of satellite data much larger than the initial one restricted to satellite cloud-free pixels coincident to in situ measurements. To ensure an estimation of the variogram representative of the situations encountered in situ, we have considered, for each clear day of our in situ sampling, a disk of satellite data centred on the barycenter of the in situ locations. Doing so, we have been able to calculate an accurate variogram on a large set of data. The slope of the in situ variogram, 0.006 , fits well the slope of the satellite variogram which is calculated for instantaneous couple of data as the satellite passes through the area in less than three minutes. The linear aspect of the variogram apparent on the in situ data is not verified for distances 
superior to 120 pixels. The satellite variogram reaches its maximum value at about 140 pixels which corresponds to about $150 \mathrm{~km}$. This distance gives the scale of the chlorophyll patterns encountered in the Bay of Biscay.

Table 2. Statistical characteristics of the estimated variables under the hypothesis of lognormality. In situ non living SPM is calculated from SPM and Chl-a using formula (15) and (16).

\begin{tabular}{|c|c|c|c|}
\hline & Chl- $a\left(\mathrm{mg} \mathrm{m}^{-3}\right)$ & non Living SPM $\left(\mathrm{g} \mathrm{m}^{-3}\right)$ & $K_{\text {PAR }}\left(\mathrm{m}^{-1}\right)$ \\
\hline $\mathrm{Nb}$ of in situ data & 1017 & 854 & 430 \\
\hline $\mathrm{Nb}$ of pairs of data & 221 & 158 & 93 \\
\hline Mean In situ & 1.75 & 1.36 & 0.25 \\
\hline Mean Satellite estimation & 1.75 & 1.37 & 0.24 \\
\hline Covariance(Sat, Situ) squared $\left(\mathrm{r}^{2}\right)$ & 0.6 & 0.59 & 0.78 \\
\hline Variance (Sat-Situ, in log) & 0.50 & 0.41 & 0.11 \\
\hline Nugget In situ & 0.1 & 0.12 & 0.08 \\
\hline Nugget satellite & 0.04 & 0.005 & 0.002 \\
\hline $\begin{array}{c}90 \% \text { Confidence interval around } \\
\text { unity }\end{array}$ & {$[0.35,2.82]$} & {$[0.42,2.42]$} & {$[0.81,1.23]$} \\
\hline
\end{tabular}

Fig. 6. Scatterplot of satellite-derived chlorophyll versus in situ chlorophyll

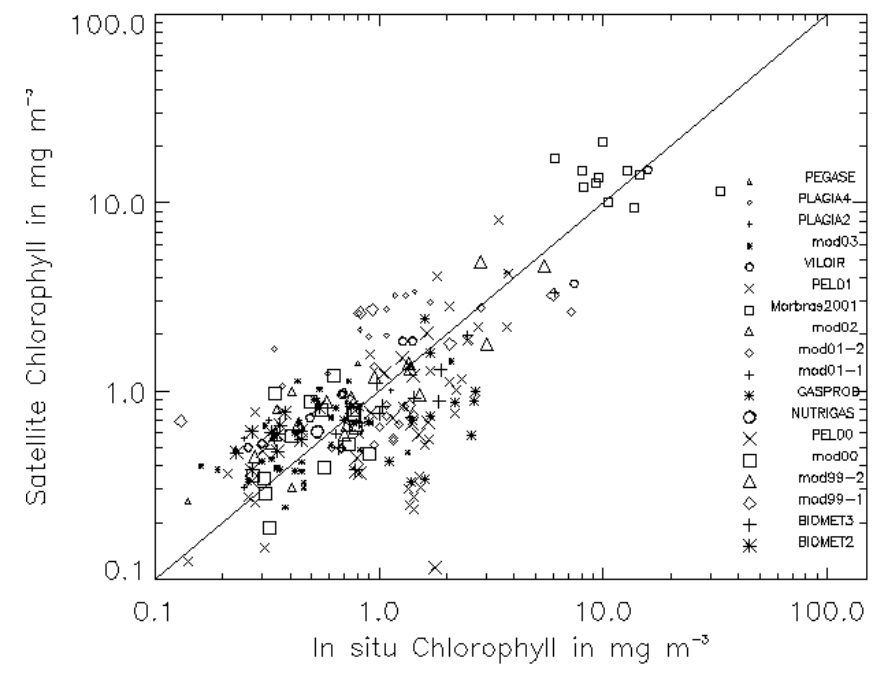


Fig. 7. Variogram of the satellite-derived chlorophyll (50 couples minimum for each class of distance)

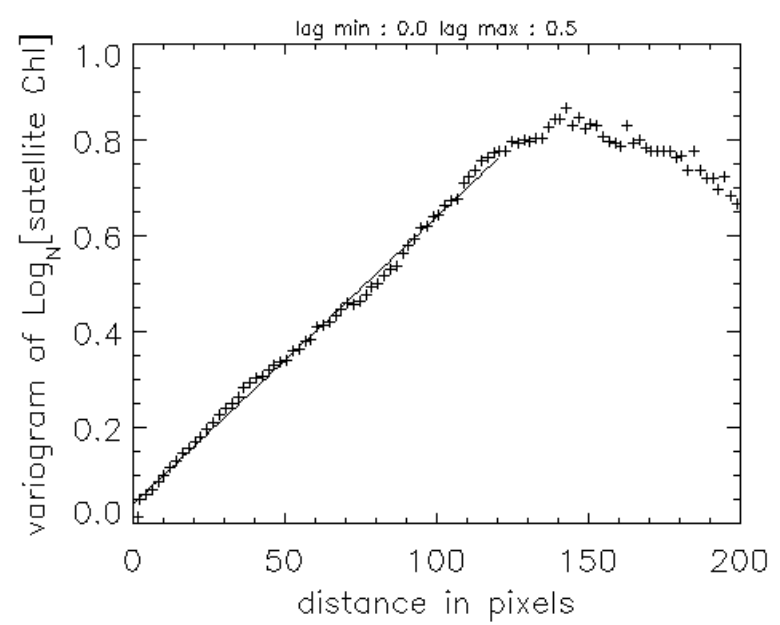

Fig. 8. Variogram of the in situ nLvSPM for couples of points separated by less than 12 hours. (50 couples minimum for each class of distance)

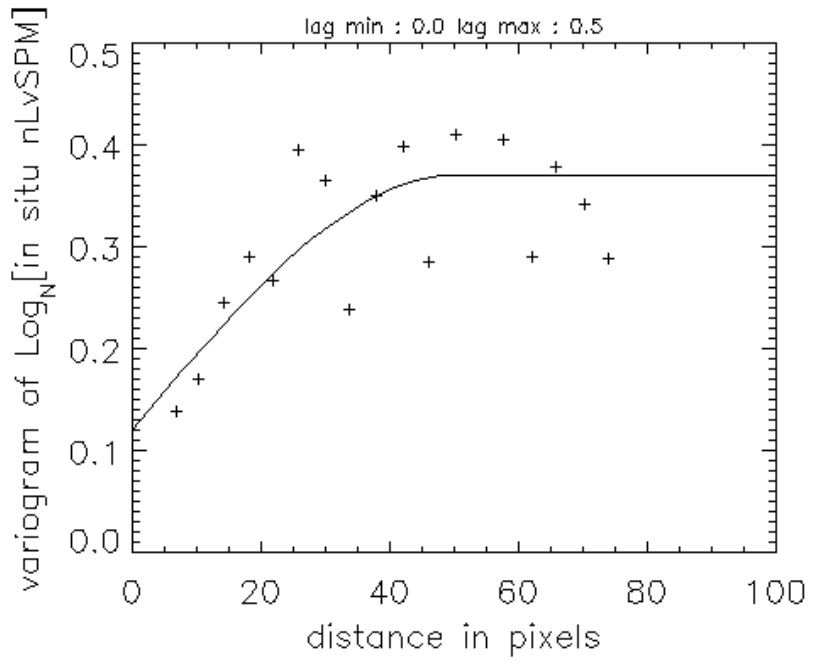




\subsection{In situ and satellite-derived $n L v S P M$}

nLvSPM is estimated by applying formulation (16) to SPM and LvSPM. If the result of formula (16) is negative, nLvSPM is set to $0.5 \mathrm{mg} / \mathrm{l}$. This high threshold is adapted to the level of the accuracy that we can reach from SeaWiFS and which is constrained by the quality of the atmospheric correction (this aspect will be developed in chapter 6.4). The experimental variogram (Fig. 8) can be fitted by a spherical variogram with a range of 50 pixels. This gives us an idea of the size of the SPM features which vary in relation with the bathymetry and the river outflows. A part of the discontinuity observed in the experimental variogram may also result of the small number of data (854 versus 1017 for chlorophyll).

Fig. 9 shows the scatterplot of $\mathrm{R}^{*}(555)$ derived from the water leaving radiance at $555 \mathrm{~nm}$, as defined in Eq. (17), versus the same quantity derived from nLvSPM and Chl. The coefficients of formula (6), (7) and (17), used in the determination of the IOPs of the water have been taken from the literature (Table 3). The estimated parameters are $\alpha_{0}=0.103$ and $\alpha_{1}=0.029$ in regression (17). Many IOPs are available in the literature and it is not our purpose here to propose a new set adapted to the Bay of Biscay. The most significant modification from the initial IOP data set that we have made is the diminution of the chl-dependency in the backscattering coefficient. Applying the initial function (Table 3) provided for case 1 waters by Morel (1988) resulted in the apparition of nLvSPM in strong blooms located in clear waters (outside of the periods sampled by our cruises) where we know that the mineral SPM is low.

Table 3. Formulation of the IOPs

\begin{tabular}{|c|c|c|}
\hline $\begin{array}{l}\text { Optical } \\
\text { Parameters at } \\
555 \mathrm{~nm} \\
\left(\text { in } \mathrm{m}^{-1}\right) \\
\end{array}$ & $\begin{array}{c}\text { Adjusted } \\
\text { Formulation }\end{array}$ & Initial formulation and reference \\
\hline$a_{w}$ & 0.064 & Prieur \& Sathyendranath (1981) \\
\hline $\mathrm{b}_{\mathrm{bw}}$ & $0.002 * 0.5$ & Smith \& Baker (1981) \\
\hline $\mathrm{b}_{\mathrm{bChl}}(\mathrm{Chl})$ & $\begin{array}{l}0.5 \mathrm{Chl}^{0.8}[0.02(0.5- \\
0.16 \mathrm{alog}(\mathrm{Chl}))]\end{array}$ & $\begin{array}{l}0.488 \mathrm{Chl}^{0.795}[0.002+0.02(0.5-0.25 \operatorname{alog}(\mathrm{Chl}))] \\
\text { Loisel \& Morel }(1998) \text { and Morel }(1988)\end{array}$ \\
\hline $\begin{array}{l}\mathrm{a}_{\mathrm{p}+\mathrm{y}}(\mathrm{Chl})= \\
\mathrm{a}_{\mathrm{p}}+\mathrm{a}_{\mathrm{y}} \text { where } \\
\mathrm{a}_{\mathrm{p}} \text { is the } \\
\text { absorption } \\
\text { coefficient of } \\
\text { particles } \\
\text { related to } \\
\text { chlorophyll }\end{array}$ & $0.02 \mathrm{Chl}^{0.8}$ & $\begin{array}{c}0.0002+0.01 \mathrm{Chl}^{0.82}+0.0066 \mathrm{Chl}^{0.62} \\
\mathrm{a}_{\mathrm{p}}=0.01 \mathrm{Chl} \mathrm{l}^{0.82} \\
\mathrm{a}_{\mathrm{y}}(555)=0.1\left[\mathrm{a}_{\mathrm{w}}(440)+\mathrm{a}_{\mathrm{p}}(440] \exp -0.0176(555-440)\right] \\
\mathrm{a}_{\mathrm{p}}(440)=0.05 \mathrm{Chl}^{0.62} \\
\text { Bricaud et al. }(1988) \\
\text { For the slope of the } \lambda \text {-dependency see : } \\
\text { Babin et al. (2003) } \\
\mathrm{a}_{\mathrm{w}}(440)=0.015 \text { from Prieur \& Sathyendranath (1981) }\end{array}$ \\
\hline $\mathrm{b}_{\mathrm{bs}}{ }^{*}(\mathrm{SPM})$ & $0.03 * 0.5(\mathrm{SPM})$ & $b_{\mathrm{s}}{ }^{*}=0.5$ in Bowers et al. (2002) and Babin et al. (2003) \\
\hline$a_{s}^{*}(S P M)$ & $0.025(\mathrm{SPM})$ & $\begin{array}{c}\mathrm{a}_{\mathrm{s}}^{*}=0.027 \text { Bowers \& Mitchelson_Jacob (1996) } \\
0.0205+0.038 \exp (-0.0055[550-440]) \\
\text { Bowers et al. }(1998)\end{array}$ \\
\hline
\end{tabular}


Fig. 9. $\frac{b_{b}[555]}{a[555]+b_{b}[555]}$ linearly derived from $n L w[555]$ versus estimation from in situ nLvSPM and chlorophyll.

Due to an overestimation of $\mathrm{nLw}$ [555] by the atmospheric correction, a positive bias is visible on this figure at low reflectance, i. e. in clear water.

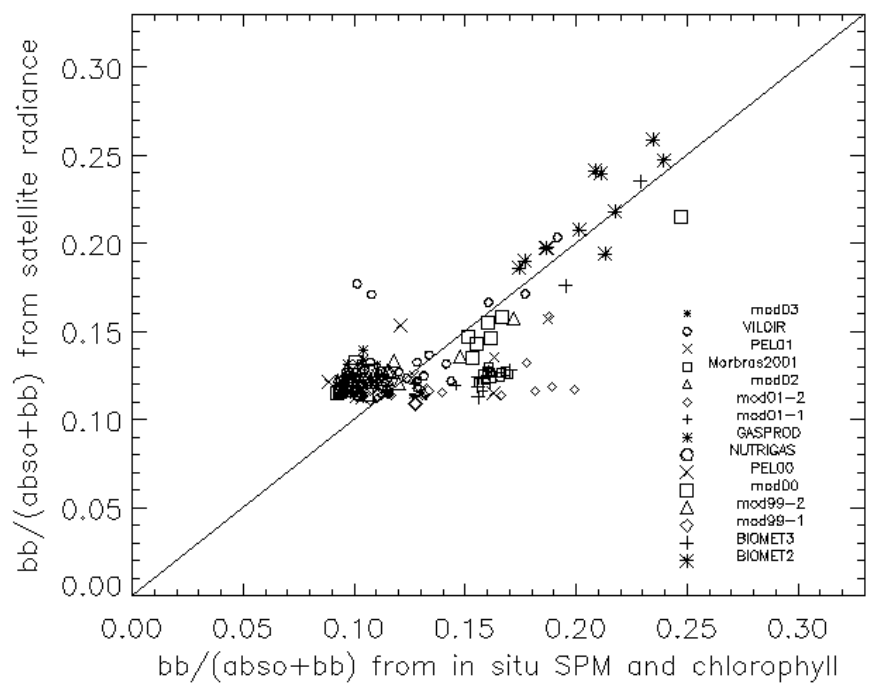

A lack of sensitivity in the satellite response is visible on Fig. 9 for low theoretical reflectance. There seems to be a threshold, at about 0.1 , for $\mathrm{R}^{*}(555)$, which will not enable an accurate estimation of nLvSPM for relatively clear water. This poor sensitivity of the satellite reflectance, certainly due to default in the atmospheric correction, affects the quality of the estimation of low nLvSPM. For low reflectance, there is a positive bias in the estimations of nLvSPM (Fig. 10). Fig.11 shows the variogram of the satellite-derived nLvSPM.

Fig. 10. Satellite nLvSPM versus nLvSPM deduced from in situ measurements of SPM and chlorophyll

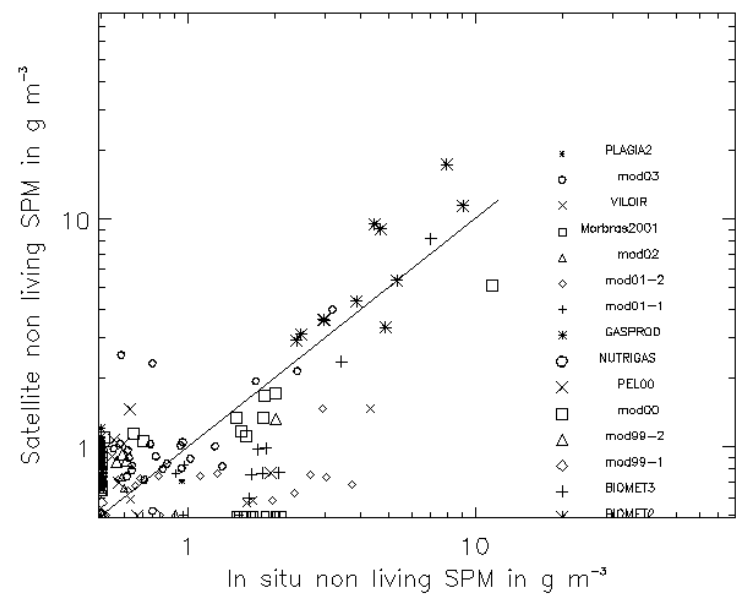


Fig. 11. Variogram of the satellite-derived nLvSPM

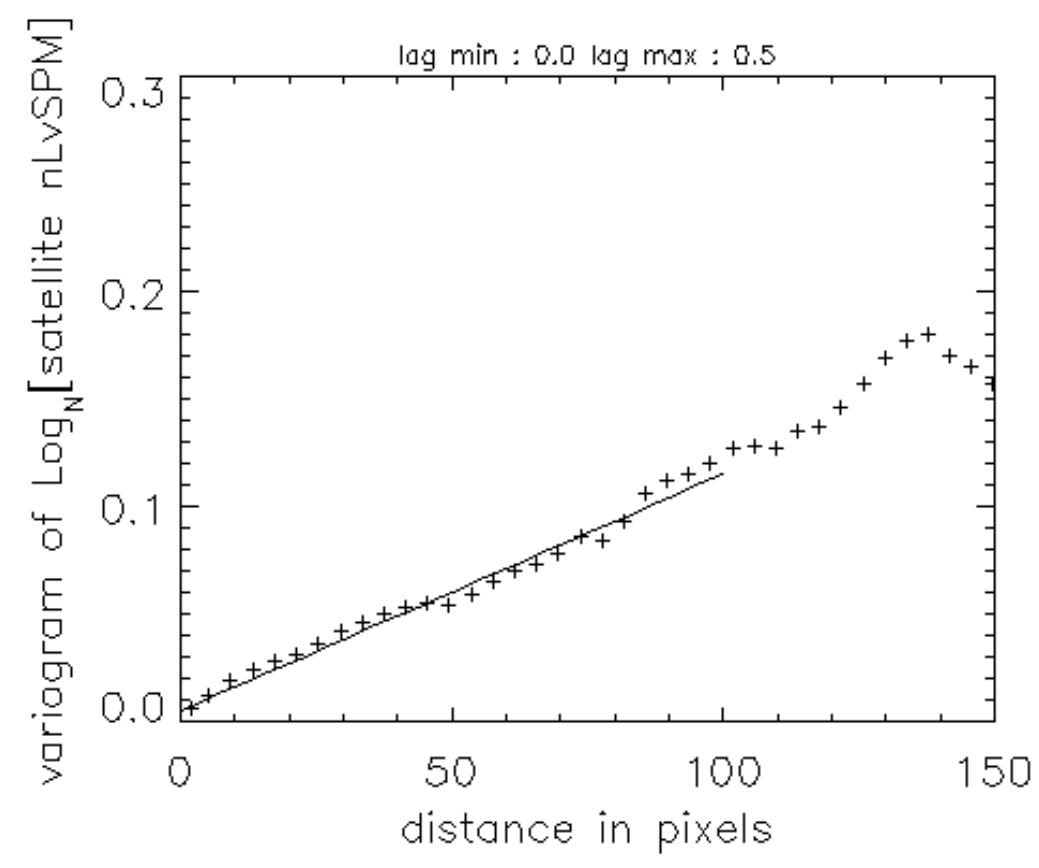

The satellite variogram is much more regular than that derived from in situ measurements. It shows a linear trend up to 120 pixels. The deviation between satellite and in situ variograms may have different origins. The first one may result from an artificial and local uniformisation observed after setting a minimum value for low or negative satellite-derived nLvSPM. The second one may be related to the sensitivity of the satellite-derived nLvSPM to the atmospheric correction. In practice, satellite nLvSPM lower than $1.0 \mathrm{~g} \mathrm{~m}^{-3}$ are not reliable and their spatial variation (amplified with the log-transformation) reflects mostly that of the atmospheric correction.

Underestimation of nLvSPM has also been observed after processing the satellite data corresponding to the MORBRAS2001 cruise which has been carried out in the vicinity of the Vilaine plume on May 23, 2001. The chlorophyll concentration measured in situ was high (between 6 and $33 \mu \mathrm{g}^{-1}$ in the Vilaine plume) and the mean satellite derived concentration is slightly overestimated (see Fig. 6). In such a situation, a relatively low error in the chlorophyll concentration has for effect a large error in the nLvSPM concentration. Low nLvSPM values have been retrieved for that cruise (see Fig. 10). More generally a possible underestimation of nLvSPM is expected in river plumes in spring, when the light quantity available is high and the chlorophyll is optically dominant.

\subsection{In situ and satellite $K_{P A R}$}

The variogram of in situ $K_{\text {PAR }}$ (Fig. 12) exhibits a poor structure which can be partly explained by the small number of data. Although it would be possible to see a small nugget effect at the origin followed by a strong spherical behaviour with a range of 20 pixels, we have considered a high nugget effect followed by a linear trend without determining any range. In consequence of the strong relationship between Chl, nLvSPM, and $\mathrm{K}_{\mathrm{PAR}}$, the variogram of $K_{\text {PAR }}$ should logically show a first trend at small distance (patterns of nLvSPM) followed by a lower trend related to the chlorophyll feature. 
$\mathrm{K}_{\mathrm{PAR}}$ is estimated from nLvSPM and Chl by Eq. (19).

The coefficient $\mathrm{k}_{1}$ and $\mathrm{k}_{2}$ in Eq. (19) have been estimated from the regression of the in situ $K_{\text {PAR }}$ on the absorption coefficient a(555) derived from Eq. (7) using the coefficients of Table 3.

$\mathrm{K}_{\mathrm{PAR}}=2.5 \mathrm{a}(555)-0.06$

Given the expression of a(555), it follows from Eq. (20) :

$\mathrm{K}_{\mathrm{PAR}}=0.1+0.0625 \mathrm{nLvSPM}+0.05 \mathrm{Chl}^{0.80}$

Fig. 12. Experimental variogram of in situ $\mathrm{K}_{\mathrm{PAR}}$ for couples of points separated by less than 12 hours. (25 couples minimum for each class of distance)

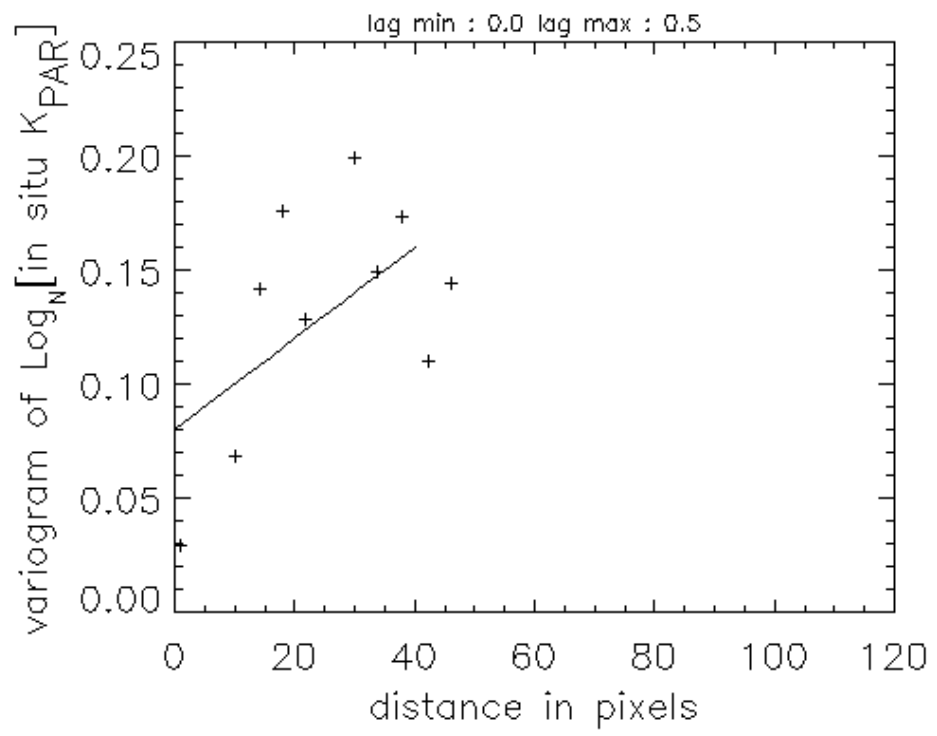

Fig. 13 shows the scatterplots of in situ and satellite $K_{\text {PAR }}$ derived from measured or estimated $\mathrm{nLvSPM}$ and Chl. The negative constant in Eq. (20) shows that the relationship between $\mathrm{K}_{\mathrm{PAR}}$ and the absorption coefficients is available only in this context where a minimum value is specified for $\mathrm{nLvSPM}\left(0.5 \mathrm{~g} \mathrm{~m}^{-3}\right)$ and therefore for the absorption coefficient. The slope appears higher than that obtained by Bowers and Mitchelson-Jacob (1996) who propose for the Irish Sea a slope of about 1.6 for a mean $\mu_{0}$ equal to 0.7 . This high slope can be partly explained by the fact that our highest $K_{\mathrm{PAR}}$ values have been obtained in winter when $\mu_{0}$ is relatively lower, which could lead to increase the estimated slope. Another effect that can be mentioned is the role of yellow substances in the attenuation of light at short wavelengths, in the blue part of the spectrum. Weak in the green and red, the attenuation by yellow substances is high around their peak of absorption in the blue. Their concentration is likely to increase with nLvSPM and Chl, and therefore with a(555). It has to be acknowledge that all the IOPs mentioned in this study, as well as the reflectance, have to be considered for what they are, simple intermediates in the estimation of nLvSPM and $\mathrm{K}_{\mathrm{PAR}}$ and not as absolute quantities as we have no direct measurement.

The variogram of the satellite $\mathrm{K}_{\mathrm{PAR}}$ is shown on Fig. 14. As a consequence of the difficulty to estimate nLvSPM in clear waters, there is a small positive bias for $\mathrm{K}_{\mathrm{PAR}}$ for low values of this 
parameter. The confidence interval around unity [0.81,1.23] is smaller than for chlorophyll and nLvSPM. This can be explained by the fact that the scale of variability is lower, from 0.1 to $1.2 \mathrm{~m}^{-1}$ in our sample, and that the errors in chlorophyll and nLvSPM concentrations derived from our procedure are negatively correlated and may compensate one each other.

Fig. 13. Estimated $\mathrm{K}_{\mathrm{PAR}}$. (a) $\mathrm{K}_{\mathrm{PAR}}$ estimated from In situ SPM and Chl ; (b) Satellite $\mathrm{K}_{\mathrm{PAR}}$ estimated from satellite-derived SPM and Chl-a
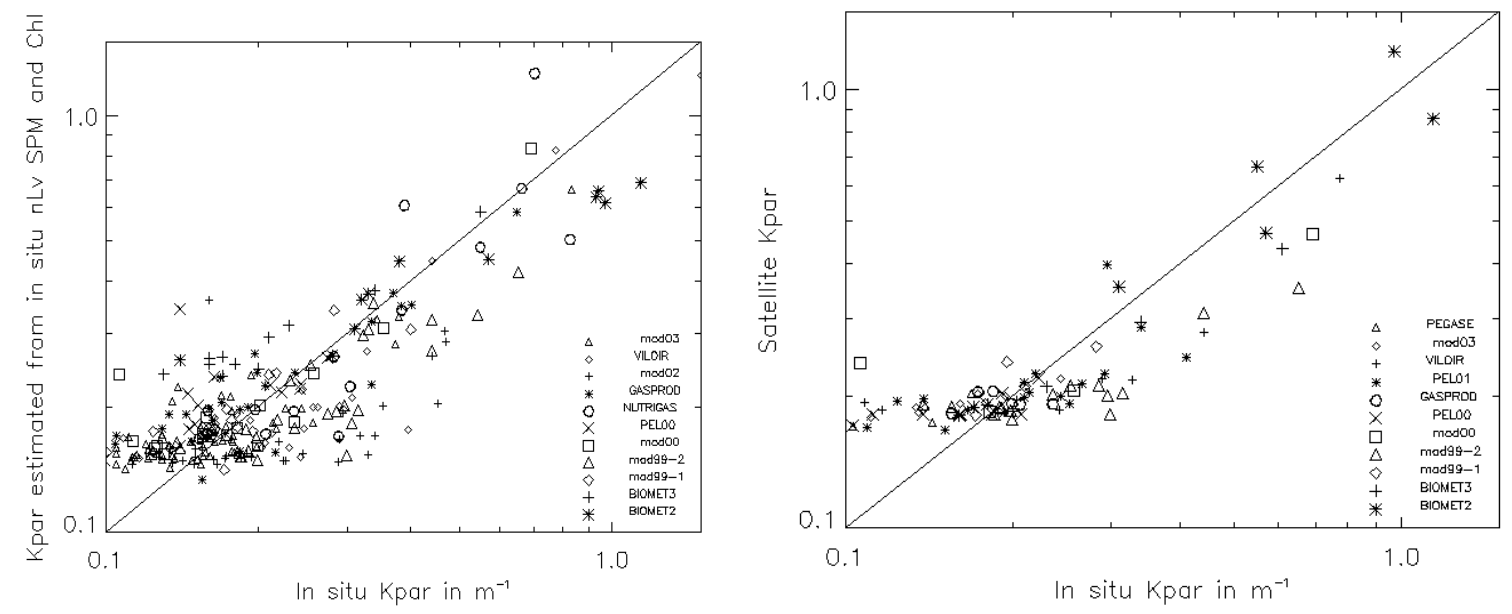

Fig. 14. Variogram of satellite $\mathrm{K}_{\mathrm{PAR}}$

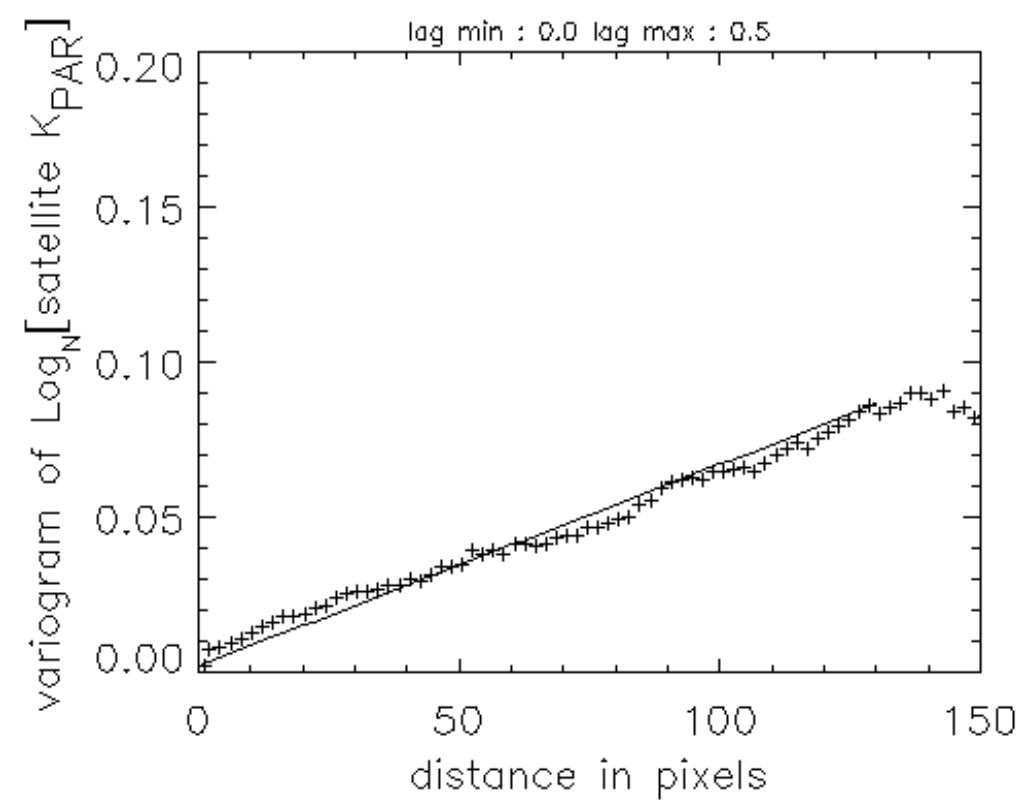




\section{Applications to typical seasonal cases and discussion}

\subsection{The seasonal variability}

The variability of our parameters is high on the continental shelf of the Bay of Biscay during the different seasons. In winter, strong storms can lead to resuspension of sediment in the surface layer, which, combined to large river outflows, can give high SPM loads over a large part of the continental shelf. The coastal area affected by such a phenomenon is not well known and the satellite can be of great use for observing it. The BIOMET2 cruise, which was carried out in January 1998, is representative of those situations where SPM is high (Froidefond et al., 2002). Late winter blooms, occurring from mid-February to March in stratified waters, regulate the yearly energetic and nutrients fluxes between the surface and the bottom. Ocean colour techniques from space are particularly well suited for studying these blooms which occur by clear sky as light is the limiting factor (Gohin et al., 2003). The NUTRIGAS cruise, carried out in February 2001, provides a typical example of the hydrological and biological environment encountered in these blooms. In summer time, the production is smaller at the surface and the chlorophyll is concentrated in the vicinity of the pycnocline. VILOIR has been selected as representative of these situation.

\subsection{A typical winter situation : BIOMET2}

BIOMET2 was carried out between the 9 and 18 January 1998, during a typical winter situation characterised by frequent storms of west, southwest winds whose speeds reached up to $25 \mathrm{~m} \mathrm{~s}^{-1}$. This physical forcing favoured the vertical mixing of the water column, leading to homogeneous profiles of salinity, temperature and Chl (profiles not shown) and high SPM values $\left(2.5 \mathrm{~g} \mathrm{~m}^{-3}\right)$ at point B located outside of the Gironde plumes (salinity $>35.5$ ), and at 90 meters depth (see point B : $2.51 \mathrm{~W}, 45.83 \mathrm{~N}$ on Fig. 15a). SeaWiFS image of nLvSPM reproduces fairly these high values of SPM offshore which have been seldom sampled in situ. SeaWiFS images of SPM and $\mathrm{K}_{\mathrm{PAR}}$ are very realistic compared to the in situ values. This winter situation characterised by high turbidity, cold waters and low sunny weather was unfavourable for the phytoplankton development (light limited) as observed by the very weak values of measured and estimated Chl (Fig.15a and 15d). 
Fig. 15. Chl- $a$, SPM, and $\mathrm{K}_{\mathrm{PAR}}$ observed in situ and derived from SeaWiFS during BIOMET2 (9-18 January 1998). (a), (b), (c), in situ measurements ; (d),(e),(f), satellite estimations on January $10^{\text {th }}$. (b) is total SPM measured in situ, (e) is estimated non Living SPM.

Point B $(2.51 \mathrm{~W}, 45.83 \mathrm{~N})$ is shown on (a).
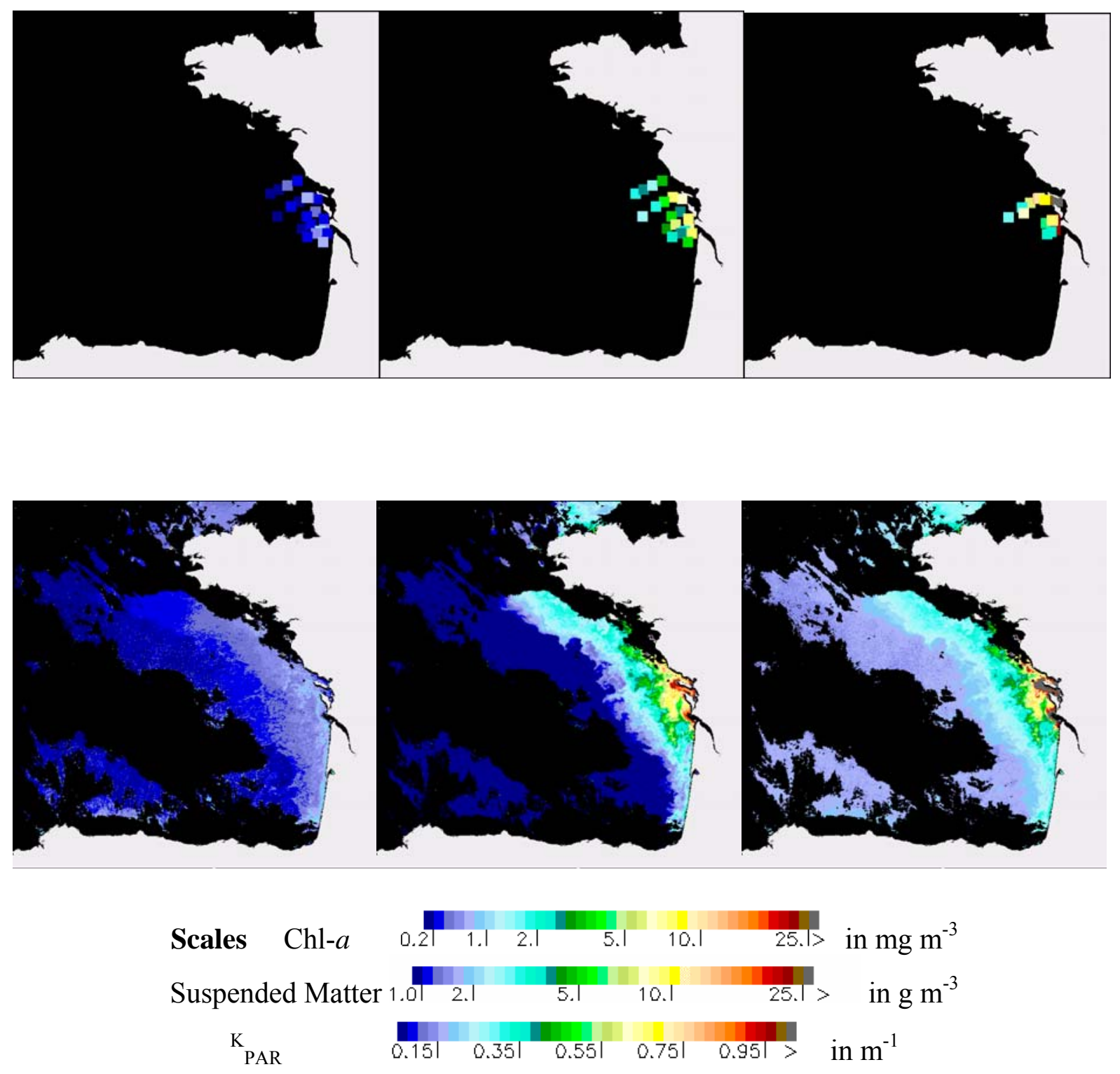

\subsection{A winter bloom in a mixed upper layer : NUTRIGAS}

The NUTRIGAS cruise was performed from 23 to 28 February 2001. Spatial distribution of salinity in the surface layer shows a large extension of the Loire plume in relation to the strong fresh water flow observed during the winter 2000-2001. A typical CTD profile (at point $\mathrm{N}: 3.69 \mathrm{~W},-46.89 \mathrm{~N}$ ) is presented on Fig. 16a, showing that a strong haline stratification was established with cold and fresh water in the upper layer. The surface fluorescence distribution revealed the presence of an early bloom of phytoplankton cells with a maximal extent located offshore southwest of Belle-Ile. Over this area, salinity and fluorescence vertical distributions from CTD profiles showed that the maximum of chlorophyll occurred out of the turbid plume of the Loire river, at a place where the surface layer was stratified and the water sufficiently clear. Microscopic observations carried out from the corresponding samples in the upper layer confirm an abundance of diatoms of large size $>$ 
$20 \mu \mathrm{m}$ (Thalassiosira, Shroderella). Phytoplankton blooms with abundance of large diatoms were already found during winter period in the Gironde plume of the Bay of Biscay (BIOMET3 cruise, Labry et al., 2001). As for BIOMET3, the early bloom observed during NUTRIGAS was initiated according to the optimal anticyclonic conditions with light wind and sunny conditions preceding the cruise. High abundance of nutrients from the Loire plume associated to maximal light irradiance gave optimal conditions for the growth and the division of the phytoplankton cells. It clearly appears that the in situ surface distribution of chlorophyll is in accordance with the satellite estimation performed on February $25^{\text {th }}$ (Fig. 17) and that high values of chlorophyll are related to low $\mathrm{K}_{\mathrm{PAR}}$ and low SPM derived from the satellite radiance. It appears that both methods were in agreement: in situ measurements and satellite observations showed that the phytoplankton biomass was maximum in the euphotic layer out of the turbid plume of the Loire river.

Fig. 16. NUTRIGAS (a) and VILOIR (b) profiles at points N $(3.69 \mathrm{~W},-46.89 \mathrm{~N})$ and V $(3.02 \mathrm{~W},-47.20 \mathrm{~N})$
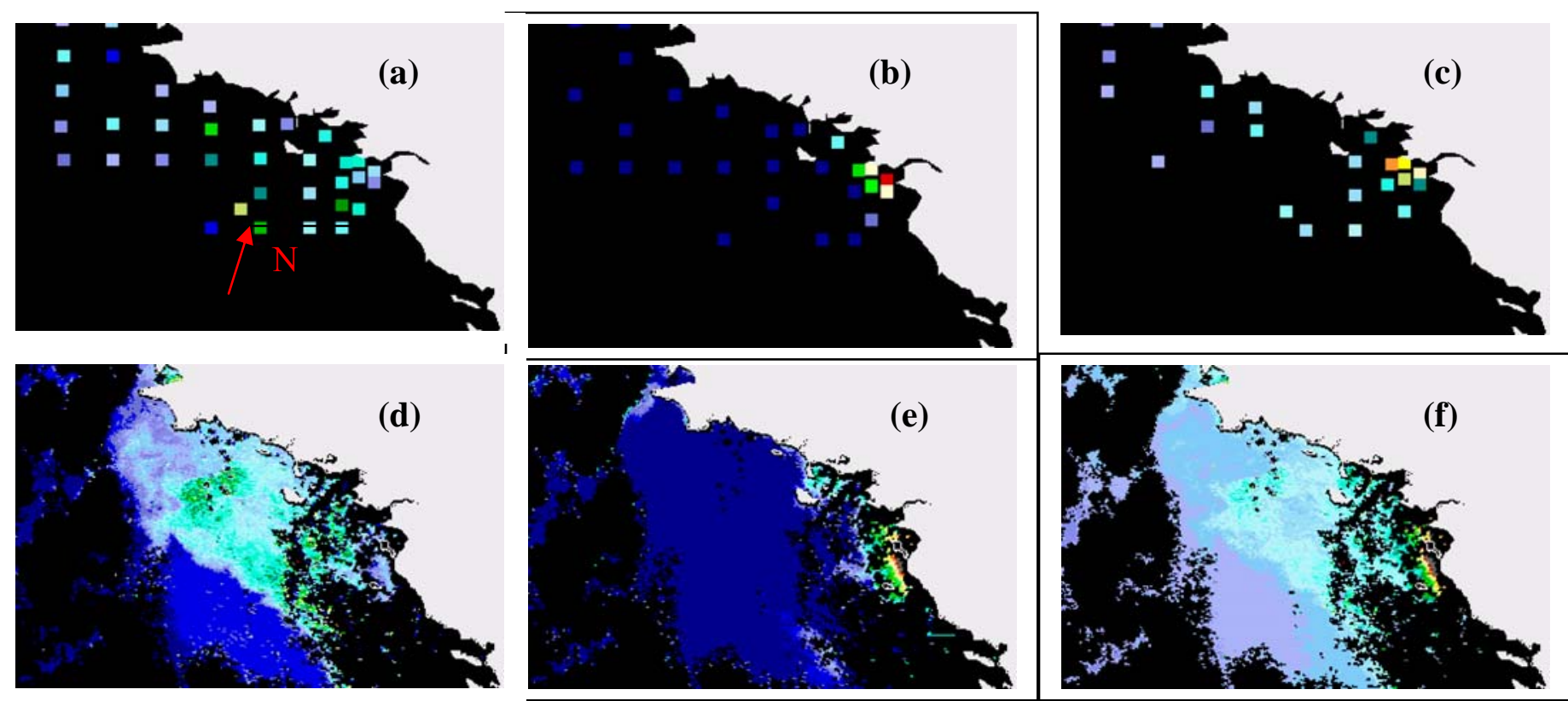

\subsection{Summer stratified coastal waters : VILOIR}

The hydrological observations of the VILOIR cruise, from 19 to 26 June 2003, are typical of summer conditions which are characterised by a decrease in the extension of the Loire plume and by the establishment of a strong thermocline in the surface layer. Conversely to NUTRIGAS, where the chlorophyll biomass was mainly distributed offshore, the summer conditions encountered during the VILOIR cruise leads to enhanced chlorophyll concentration in the coastal turbid waters (Fig. 18). Studies on horizontal and vertical distributions of in situ chlorophyll revealed the presence of two distinct maxima. First one was located in the mouth of the Loire river where the chlorophyll was homogeneously distributed in the mixed water column. Second maximum, reaching $4 \mu \mathrm{g} .1^{-1}$, was measured offshore, in the stratified area, and the higher values of chlorophyll were located in the thermocline above the salty oceanic waters (Fig.16b). Those results are in accordance with previous studies which demonstrated that, in summer, the rate of phytoplankton production in the surface layer of the Bay of Biscay is mainly constrained by nutrients. The chlorophyll maxima are located at about 20 meters depth, in the stratified zone, over oceanic waters with higher concentrations in nutrients (Morin, 1991; Longhurst, 1998). 
Fig.18. Chl- $a$, SPM, and $\mathrm{K}_{\mathrm{PAR}}$ observed in situ and derived from SeaWiFS during VILOIR (19-26 June 2003). (a), (b), (c), in situ measurements ; (d),(e),(f), satellite estimations on June $20^{\text {th }}$. (b) is total SPM measured in situ, (e) is estimated non Living SPM and coccoliths.
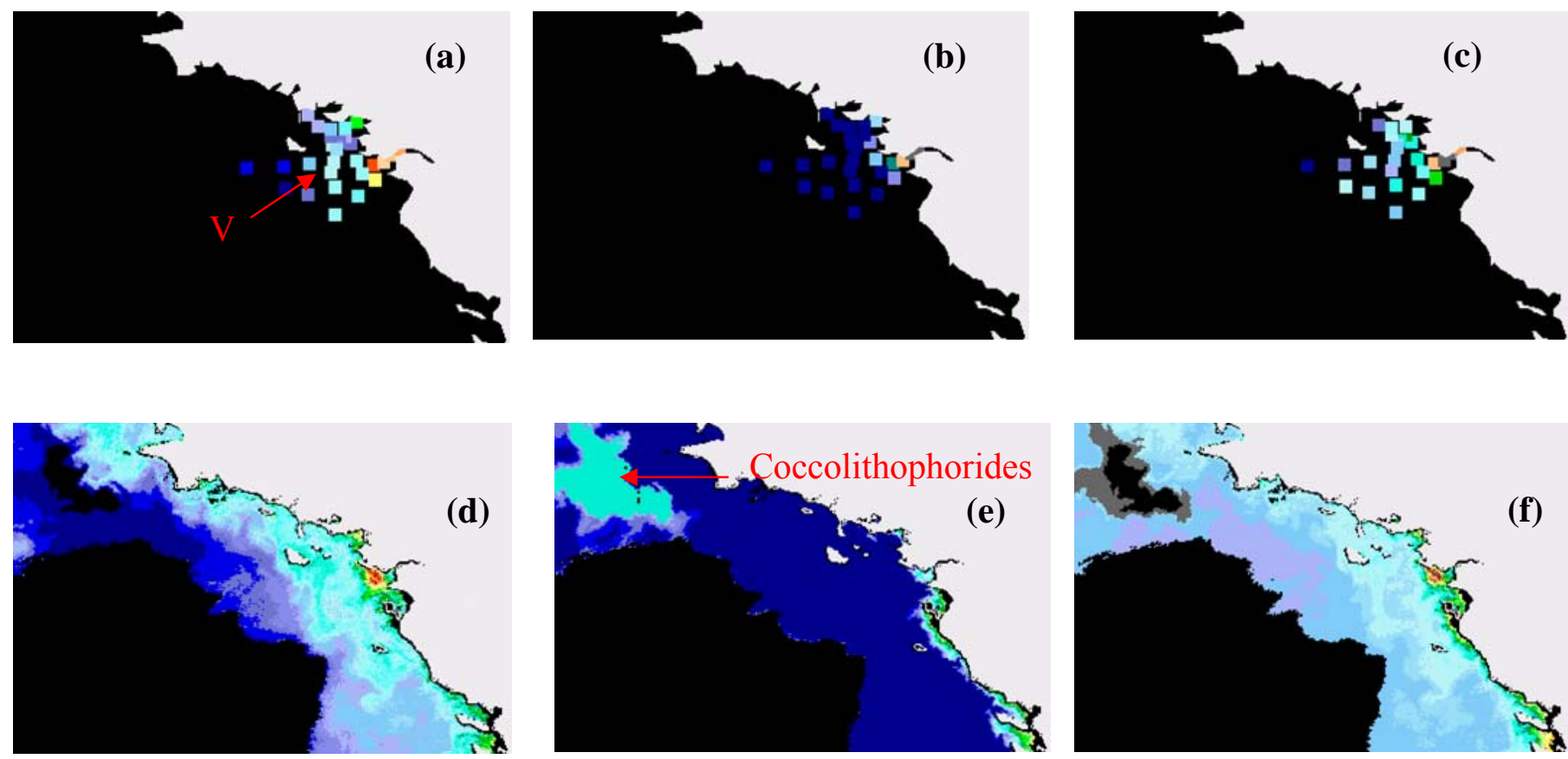

We observe, see Fig. 18d, that the satellite-derived chlorophyll concentration is rather low in the estuary of the Loire river when compared to the in situ measurements. Our look-up table used for estimating the chlorophyll, empirically designed, tends to diminish too strongly the estimated chlorophyll in turbid waters from mid-spring to the beginning of summer when the solar irradiance is high and the productivity can be significant, even in turbid water. Selected for its excellent results in winter time when a clear water algorithm as OC2 or OC4 is totally inadequate, our look-up table could diminish excessively the level in chlorophyll in the most turbid waters when the solar irradiance is high. However, the diminution in chlorophyll is not compensated by a strong increase in nLvSPM and the estimated $\mathrm{K}_{\mathrm{PAR}}$ decreases from the outer to the inner part of the plumes which is surprising as it is the light limitation which prevents the occurrence of a maximum in the chlorophyll concentration in the estuary (Fig. $18 \mathrm{a}$ and $\mathrm{b}$ ). However, the other images, partially cloud-free, available during the VILOIR cruise (not shown) present higher chlorophyll values in the estuary. In case of high chlorophyll concentration, an underestimation of nLvSPM may be expected. Another interesting feature on the image displayed on Fig. 18e is the coccolithophorides bloom in the "Mer d'Iroise", south of the Celtic Sea. Coccolithophorides are very common at that period of the year. They are easily identified from their radiance properties. Similarly to other SPM, they increase strongly the reflectance at $555 \mathrm{~nm}$ but, conversely to nLvSPM which is mainly located in waters absorbing the low wavelength radiations, $\mathrm{nL}_{\mathrm{W}}(412)$ remains at high level in presence of coccolithophorides.

\subsection{Effect of SPM on the quality of the chlorophyll concentration derived from OC4}

OC4 has been defined for clear waters (Case 1) and it is well known that the application of this algorithm to coastal waters leads to overestimation in the chlorophyll concentration. However, awaiting achievement of a complex procedure dedicated to Case 2 waters, OC4 is 
still very often applied indiscriminately in operational and routine processing of SeaWiFS data. The deviation between monthly chlorophyll concentrations, derived from OC4 and from our look-up table, averaged from 1998 to 2003, can be interpreted with regard to the SPM level and the light ability at the surface; this latter favouring the role of the chlorophyll in the IOPs of the water and the seasonal Case 2 to Case 1 transition from winter to summer. The OC4 algorithm is based on the blue/green reflectance ratio. Chlorophyll pigment concentration is inversely related to this ratio. In three cases, this ratio can be altered towards lower values by materials other than chlorophyll. Yellow substances, absorbing in the blue, SPM, scattering in the green, atmospheric correction errors enhanced in the blue, can dramatically decrease the blue/green ratio. In coastal waters, all these effects occur simultaneously. However, while the OC4 ratio is altered by yellow substances in the Baltic Sea (Darecki \& Stramski, 2004), this study shows that it is largely affected by SPM, with an unknown contribution of the yellow substances, over the continental shelf of the Bay of Biscay. As expected, the application of OC4 to the SeaWiFS water leaving radiance overestimates considerably the chlorophyll concentration in January and February (Fig. 19), when SPM is high and light is low, and tends to a more realistic value in May and June. Therefore, if we define as Case 2 the waters where materials other than phytoplankton are optically dominant, it would be possible to statistically classify the waters in type for any time and any location on the continental shelf of the Bay of Biscay. Most of the waters in June are optically dominated by chlorophyll and can be defined as Case 1 waters, though they are mostly Case 2 waters in January. In fact, there is a regular increase in the area where the load in surface sediment is high from October to January and a fast decrease from March to May. 


\section{Figure 19}

Fig. 19. Bimonthly averages (January to June) of non living SPM and chlorophyll-a, derived from application of OC4 and from the IFREMER look-up table
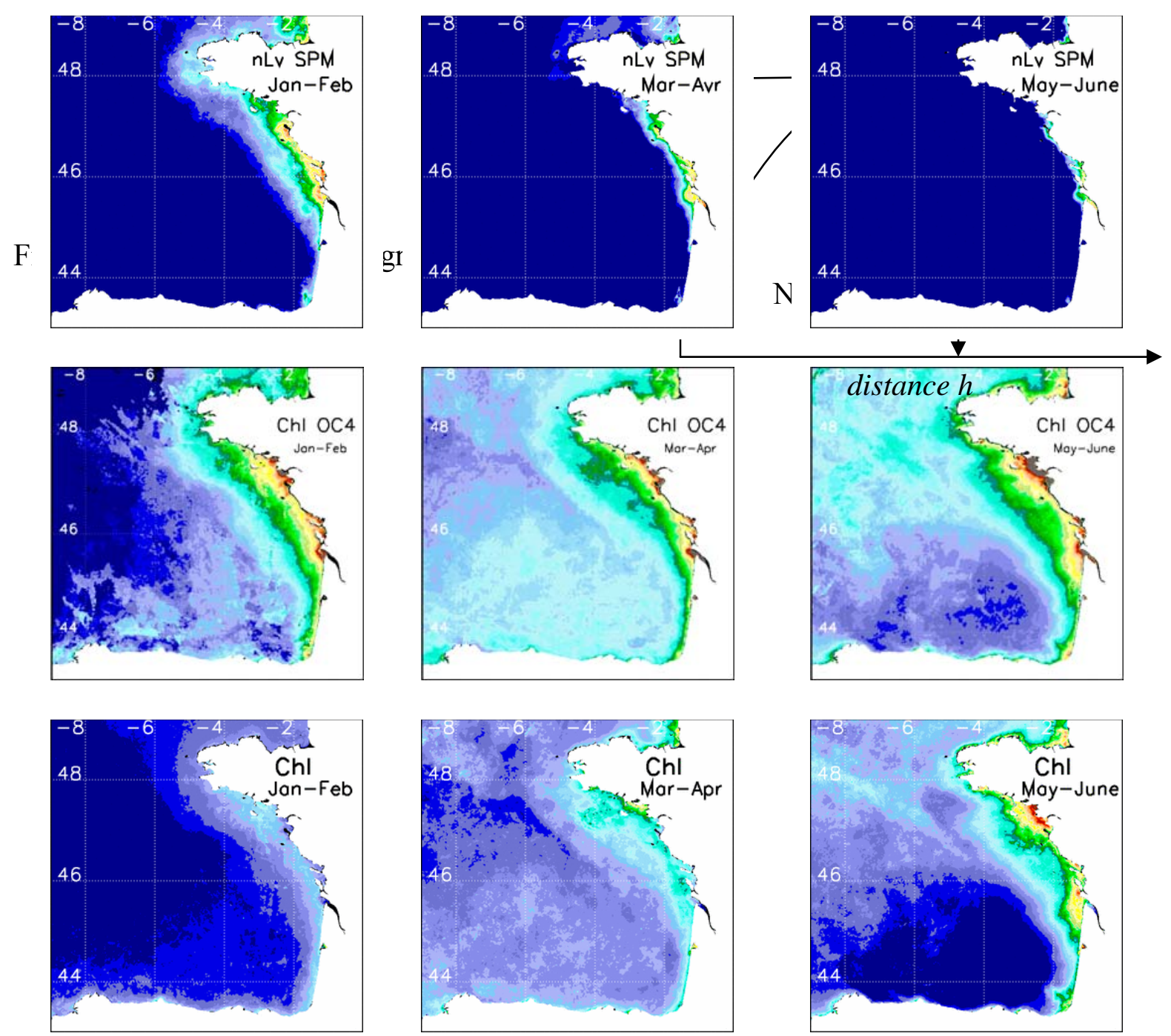

SPM :
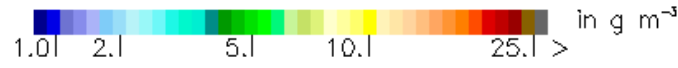

Chl-a : 0.2

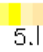

5.1

\section{Discussion}

The empirical table used for retrieving the chlorophyll concentration from the SeaWiFS water leaving radiance has been tested on a large set of data. Satellite and in situ chlorophyll concentrations have been compared through their means and their variograms. The results have shown that the satellite chlorophyll concentration does well represent the chlorophyll patterns, in their level and their spatial structure. This study confirms the capacity of the optical techniques applied to SeaWiFS for retrieving chlorophyll concentration in Case 2 waters and gives also a clear idea of the limitation of the method. The evaluation of the satellite products has been made in an operational sense, i.e. without any individual selection on the measurements and on the satellite pixels, excepted the SeaDAS cloud flag. Due to uncertainties in the atmospheric correction, the non living SPM is not estimated with an 
accuracy similar to that reached for chlorophyll at low concentration of particles. The inversion of the reflectance at $555 \mathrm{~nm}$ makes the algorithm very sensitive to error in the evaluation of the contributions of the atmosphere and the white caps to the radiance reaching the sensor. However, this study provides an order of magnitude of the estimation errors.

The similarity between the experimental, satellite and in situ, variograms of chlorophyll reflects the quality of the structures revealed by the satellite sensor. The variograms of in situ and satellite nLvSPM and $\mathrm{K}_{\mathrm{PAR}}$ appeared to be less informative than that of chlorophyll. Many reasons converge for that. First of all, nLvSPM does not verify the conditions of stationnarity required for defining a variogram. The repetitivity in the nlvSPM patterns is less apparent than that of chlorophyll and the small number of data makes the estimation of the empirical variogram still more difficult. In the nLvSPM and $\mathrm{K}_{\mathrm{PAR}}$ cases, the variograms have only been used for assessing the nugget effect and the mean behaviour of the variance of the in situ data at small distances.

Chlorophyll and nLvSPM can be considered as very complementary variables, in their patterns, but also in the way they are obtained. The chlorophyll concentration is highly dependent on the spectral shape of the reflectance, with estimation based on reflectance ratios, whereas the non living SPM is derived from the absolute value of the reflectance in the green channel. Therefore, we can consider that a large part of the information contained in the SeaWiFS radiance lies in these two maps. However, we are aware that our method is not fully consistent as an analytical procedure is proposed for estimating nLvSPM and not for the chlorophyll. Our analytical formulation is restricted to the $555 \mathrm{~nm}$ wavelength where the yellow substances have little influence on the water leaving radiance. The extension of the optical parametrisation to the whole visible domain for calculating $K_{P A R}$ would need a spectral characterisation of the IOPs for the different materials present in the water. In fact, without taking into account the atmosphere-ocean system, as proposed for MERIS by Moore et al. (1999), it will be impossible to start a true analytical scheme of the radiative transfer in case 2 waters. Our method can be considered as a substitute to OC4 for the monitoring of the coastal waters by remote sensing while awaiting a more analytical procedure.

\section{Conclusion}

The application of the SPM algorithm to daily SeaWiFS images has brought a substantial improvement in the knowledge of the suspended matter variability and of the light availability for phytoplankton growth throughout the different seasons in the Bay of Biscay. A new representation of SPM in plumes and resuspension from October March has been made available thanks to SeaWiFS. The $\mathrm{K}_{\mathrm{PAR}}$ maps derived from SeaWiFS will provide useful conditions for modelling the late winter and spring blooms.

For this reason, in order to fully use the potential of this sensor in our coastal waters, we will provide to the scientific community nLvSPM and $\mathrm{K}_{\mathrm{PAR}}$ maps, in complement to the chlorophyll maps, through all the IFREMER's image browsers, located in the Bay of Biscay, the English Channel and the Southern North Sea. The IOPs used in the formulation of the reflectance at $555 \mathrm{~nm}$ will be adjusted for these areas. The method will be applied to MODIS and MERIS for which we may hope a better atmospheric correction and an increased sensitivity. An extension of this procedure, from SeaWiFS to higher resolution data, like those of SPOT which has a channel centred on $550 \mathrm{~nm}$, will also be undertaken in the near future. Despite the empirical character of our procedure, the daily processing of SeaWiFS images has opened the way to a large panoply of applications. Amongst them are the monitoring of the phytoplankton concentration but also the water quality, through turbidity and SPM. As it deals with long term tendencies in the evolution of many coastal regions and 
in the possible degradation of their quality, the concern of increasing turbidity in the coastal waters is more and more evoked by the water management agencies.

\section{Acknowledgements:}

The authors would like to thank the SeaWiFS Project and the Distributed Active Archive Center at the Goddard Space Flight Center, Greenbelt, MD 20771, for the production and distribution of the SeaWiFS data acquired at the Dundee station. We are also indebted to NASA for providing the SeaDAS software. We are extremely grateful to all who provided the field measurements and to Alain Aminot and David Bowers for their help concerning questions related to their field of experience. This work has been supported by the PNEC (Programme National d'Environnement Côtier) and by the IFREMER défi "Golfe de Gascogne".

The look-up table is available at request to the authors (Francis.Gohin@ifremer.fr). Two IDL routines can be provided to read the table for deriving estimates of the chlorophyll-a concentration from mapped Level-2 SeaDAS radiance.

\section{REFERENCES}

Babin, M., Stramski, D., Ferrari, G. M., Claustre, H., Bricaud, A., Obolensky, G., \& Hoepffner, N., (2003a). Variations in the light absorption coefficients of phytoplankton, nonalgal particles, and dissolved organic matter in coastal waters around Europe. Journal of Geophysical Research, 108 (C7), 3211, doi:10.1029/2001JC000882.

Babin, M., Morel, A., Fournier-Sicre, V., Fell, F. \& Stramski D., (2003b). Light scattering properties of marine particles in coastal and open ocean waters as related to the particle mass concentration. Limnology and Oceanography, 48(2), 843-859.

Bowers, D.G., \& Mitchelson-Jacob E. G. (1996). Inherent optical properties of the Irish Sea determined from underwater irradiance measurements. Estuarine, Coastal and Shelf Science, 43, 433-447.

Bowers, D.G., Boudjelas, S., \& Harker, G.E.L. (1998) The distribution of fine suspended sediments in the surface waters of the Irish Sea and its relation to tidal stirring. International Journal of Remote Sensing, 19, 2789-2805.

Bowers, D.G., Gaffney, S., White, M., \& Bowyer, P. (2002). Turbidity in the southern Irish Sea. Continental Shelf Research, 22, 2115-2126.

Bricaud, A., Morel, A., Babin, M., Allali, K., \& Claustre, H.(1998). Variations of light absorption by suspended particles with chlorophyll a concentration in oceanic (case 1) waters: Analysis and implications for bio-optical models. Journal of Geophysical Research, 103, C13, 31,033-31,044.

Cugier, P. (1999). Modélisation du devenir à moyen terme dans l'eau et le sédiment des éléments majeurs $(\mathrm{N}, \mathrm{P}, \mathrm{Si}, \mathrm{O})$ rejetés par la Seine en baie de Seine. Thèse de doctorat, Univ. de Caen, 241 p. 
Cugier, P., Ménesguen, A., \& Guillaud, J. F. Three dimensional (3D) ecological modelling of the Bay of Seine (English Channel, France) submitted to Journal of Sea Research.

Curran,P.J. (1988). The semi-variogram in remote sensing: an introduction. Remote Sensing of Environment, 24, 493-507.

Darecki, M., \&. Stramski, D. (2004), An evaluation of MODIS and SeaWiFS bio-optical algorithms in the Baltic Sea. Remote Sensing of Environment, 89, 326-350.

Defant, A. (1961). Physical Oceanography. Pergamon Press, New-York Vol. 1, 729p

Etcheber, H. (1981). Comparaison de diverses méthodes d'évaluation des teneurs en matières en suspension et en carbone organique particulaire des eaux marines du plateau continental aquitain. Journal de Recherche Océanographique, Vol. VI, Bulletin n¹, 37-42.

Froidefond, J.M., Lavender S., Labordes P., Herbland A., \& Lafon V. (2002). SeaWiFS data interpretation in a coastal area in the Bay of Biscay. International Journal of Remote Sensing, 23, 881-904.

Gohin, F., \& Langlois, G. (1993). Using geostatistics to merge in situ measurements and remotely-sensed observations of sea surface temperature. International Journal of Remote Sensing, 14, 9-19.

Gohin, F., Druon, J.N., \& Lampert, L. (2002). A five channel chlorophyll concentration algorithm applied to SeaWiFS data processed by SeaDAS in coastal waters. International Journal of Remote Sensing, 23, 1639-1661.

Gohin, F., Lampert, L., Guillaud, J.F., Herbland, A., \& Nézan, E. (2003). Satellite and in situ observations of a late winter phytoplankton bloom in the northern Bay of Biscay. Continental Shelf Research, 23, 1117-1141.

Gordon, H.R., Brown, O.B., \& Jacobs, M.M. (1975). Computed relationships between the inherent and apparent optical properties of a flat homogeneous ocean. Applied Optics, 14, $417-427$.

Gordon, H.R., \& McCluney, W.R. (1975). Estimation of the depth of sunlight penetration in the sea for remote sensing. Applied Optics, 14, 413-416.

Gregoire, M., Brasseur, P., \& Lermusiaux, P.F.J. (2003). The Use of Data Assimilation in Coupled Hydrodynamic, Ecological and Bio-geochemical Models of the Ocean. Selected papers from the $33^{\text {rd }}$ International Liege Colloquium on Ocean Dynamics, Liege, Belgium on 7-11 May 2001.

Hedger, R.D., Atkinson, P.M., \& Malthus, T.J. (2001). Optimizing sampling strategies for estimating mean water quality in lakes using geostatistical techniques with remote sensing. Lakes and Reservoirs Research and Management, 6, 279-288.

Kirk, J.T.O. (1983). Light and Photosynthesis in Aquatic Ecosystems, Cambridge University Press, Cambridge, U.K. 
Kirk, J.T.O. (1984). Dependence of the relationship between inherent and apparent optical properties of water on solar attitude. Limnology and Oceanography,35, 1486-1582.

Labry C., A. Herband, D. Delmas, P. Laborde, P. Lazure, J.M. Froidefond, A.M. Jegou \& Sautour, B., (2001). Initiation of winter phytoplankton blooms within the Gironde Plume waters in the Bay of Biscay. Marine Ecology Progress Series, 212, pp. 117-130.

Loisel, H., \& Morel, A. (1998). Light scattering and chlorophyll concentration in case 1 waters : A reexamination. Limnolology and Oceanography, 847-858.

Longhurst, A. (1998). Ecological Geography of the Sea. Academic Press, San Diego, 385pp.

Loyer, S. (2001). Modélisation de la production phytoplanctonique dans la zone côtière atlantique enrichie par les apports fluviaux. Thèse de Doctorat de l'Université de Paris VI, $232 \mathrm{p}$.

Menesguen, A., Guillaud, J.F., Aminot A, \& Hoch, T. (1995). Modelling the eutrophication process in a river plume : The Seine case study (France). Ophelia, 42, pp. 205-255.

Moore, G.F., Aiken, J., \& Lavender, S. J. (1999). The atmospheric correction of water colour and the quantitative retrieval of suspended particulate matter in case II waters: application to MERIS. International Journal of Remote Sensing, 20,1713-1733.

Morel, A. (1988). Optical modelling of the upper ocean in relation to its biogeneous matter content (Case 1 water). Journal of Geophysical Research, 93, 10749-10768.

Morel, A., Voss, J.V., \& Gentilli, B. (1995). Bidirectional reflectance of oceanic water : a comparison of modeled and measured upward radiance. Journal of Geophysical Research, $100,143-151$.

Morin P., P. Le Corre, Y. Marty \& L'Helguen, S. (1991). Evolution printanière des éléments nutritifs et du phytoplankton sur le plateau continental armoricain (Europe du Nord-Ouest). Oceanologica Acta, 14, pp. 263-279.

Mueller, J.L. (2000). SeaWiFS algorithm for the diffuse attenuation coefficient, K[490],using water-leaving radiances at 490 and $555 \mathrm{~nm}$. SeaWiFS postlaunch calibration and validation analyses, Part 3 .NASA TM-2000-206892,Vol 11 ,NASA GSFC, Greenbelt, MD. pp 24-27.

Nelson, D.M., \& Smith, W.O. (1991). Sverdrup revisited : Critical depths, maximum chlorophyll levels, and the control of Southern Ocean productivity by the irradiance-mixing regime. Limnology and Oceanography, 36, 1650-1661.

O’Reilly, J.E., Maritorena, S., Mitchell, B.G., Siegel, D.A., Carder, K.L., Garver, S.A., Kahru, M., \& Mcclain, C. (1998). Ocean color chlorophyll algorithms for SeaWiFS. Journal of Geophysical Research, 103, 24937-24953.

Prieur L., \& Sathyendranath, S. (1981). An optical classification of coastal and oceanic waters based in the specific spectral absorption curves of phytoplankton pigments, dissolved organic matter and other particulate materials. Limnology and Oceanography, 26, 671-689. 
Redfield, A.C., Ketchum, B.H., \& Richards, F.A. (1963). The influence of organisms on the composition of sea water. In: Hill, M.N. (Ed.), The Sea (Vol 2), Wiley Interscience, NewYork, pp. 26-77.

Smyth, T.J., Moore, G.F., Groom, S.B., Land, P.E., \& Tyrell, T. (2002). Optical modeling and measurements of a coccolithophore bloom,. Applied Optics, 41, 7679-7688.

Sydor, M., \& Arnone, R. (2002). Effect of suspended particulate and dissolved organic matter on remote sensing of coastal and riverine waters. Applied Optics, 36, 6905-6912.

Wright, S.W., Jeffrey, S.W., Mantoura, R.F., Llewellyn, C.A., Bjoernland, T., Repeta, D., \& Welschmeyer, N. (1991). Improved HPLC method for the analysis of chlorophylls and carotenoids from marine phytoplankton. Marine Ecology Progress Series, 77, 183-196. 